NBER WORKING PAPER SERIES

\title{
DO INSURERS RISK-SELECT AGAINST EACH OTHER? EVIDENCE FROM MEDICAID AND IMPLICATIONS FOR HEALTH REFORM
}

\author{
Ilyana Kuziemko \\ Katherine Meckel \\ Maya Rossin-Slater \\ Working Paper 19198 \\ http://www.nber.org/papers/w19198
NATIONAL BUREAU OF ECONOMIC RESEARCH
1050 Massachusetts Avenue
Cambridge, MA 02138
July 2013

We are grateful to Janet Currie, Tal Gross, Jon Gruber, Kate Ho, Melissa Kearney, Wojciech Kopczuk, Doug Miller and Andrea Prat for their feedback as well as seminar participants at Brookings, Columbia University, Princeton University, the University of Stavanger, and the University of Virginia. We are indebted to Doneshia Ates, Marc Montrose, and Gene Willard at the Texas Department of State Health Services (DSHS) for assistance with the data, as well as Stephanie Goodman and David Palmer, the Spokesperson and Chief Actuary at the Texas DSHS, respectively. Abraham Bae provided excellent research assistance. Meckel is grateful for support from a Graduate Research Fellowship from the National Science Foundation. The content is solely the responsibility of the authors and does not necessarily represent the official views of the National Science Foundation. All remaining errors are our own. The views expressed herein are those of the authors and do not necessarily reflect the views of the National Bureau of Economic Research.

NBER working papers are circulated for discussion and comment purposes. They have not been peerreviewed or been subject to the review by the NBER Board of Directors that accompanies official NBER publications.

(C) 2013 by Ilyana Kuziemko, Katherine Meckel, and Maya Rossin-Slater. All rights reserved. Short sections of text, not to exceed two paragraphs, may be quoted without explicit permission provided that full credit, including (C) notice, is given to the source. 
Do Insurers Risk-Select Against Each Other? Evidence from Medicaid and Implications for Health Reform Ilyana Kuziemko, Katherine Meckel, and Maya Rossin-Slater NBER Working Paper No. 19198

July 2013

JEL No. H4,I13,I14,J13

\begin{abstract}
Increasingly in U.S. public insurance programs, the state finances and regulates competing, capitated private health plans but does not itself directly insure beneficiaries through a public fee-for-service (FFS) plan. We develop a simple model of risk-selection in such settings. Capitation incentivizes insurers to retain low-cost clients and thus improve their care relative to high-cost clients, who they prefer would switch to a competitor. We test this prediction using county transitions from FFS Medicaid to capitated Medicaid managed care (MMC) for pregnant women and infants. We first document the large health disparities and corresponding cost differences between blacks and Hispanics (who make up the large majority of Medicaid enrollees in our data), with black births costing nearly double that of Hispanics. Consistent with the model, black-Hispanic infant health disparities widen under MMC (e.g., the black-Hispanic mortality gap grows by 42 percent) and black mothers' pre-natal care worsens relative to that of Hispanics. Remarkably, black birth rates fall (and abortions rise) significantly after MMC - consistent with mothers reacting to poor care by reducing fertility or plans discouraging births from high-cost groups. Implications for the ACA exchanges are discussed
\end{abstract}

Ilyana Kuziemko

Columbia University

Graduate School of Business

3022 Broadway

Uris Hall

New York, NY 10027

and NBER

ik2216@columbia.edu

Katherine Meckel

Columbia University

Department of Economics

New York, NY 10027

khm2110@columbia.edu
Maya Rossin-Slater

2127 North Hall

University of California

Santa Barbara, CA 93106

Mail Stop 9210

mrossin@econ.ucsb.edu 


\section{Introduction}

Increasingly in U.S. public insurance programs, the state finances and regulates competing, capitated private insurance plans but does not itself directly insure beneficiaries through a public fee-for-service (FFS) plan. Whereas Medicare debuted in 1965 as a traditional publicly administered FFS program, the 2010 Affordable Care Act (ACA) will expand insurance coverage almost entirely through this new private model. The ACA insurance exchanges offer private, capitated insurance plans with substantial government subsidies and regulation, but no public FFS option. The large majority of the ACA Medicaid expansion will occur under this private model as well, as most states have switched from FFS Medicaid to Medicaid Managed Care (MMC), where Medicaid enrollees choose from private, capitated plans with no FFS option. ${ }^{1}$ There is substantial support for similarly changing Medicare - while it currently offers a traditional public FFS plan that competes alongside private, capitated Medicare Advantage (MA) plans, in 2011 the House of Representatives passed a bill eliminating the FFS option. ${ }^{2}$

The possibility that insurers or providers would avoid high-risk individuals is a central concern for any insurance program (Newhouse, 1996), yet the existing evidence on riskselection does not directly apply to the setting we describe above. Much of the research on risk-selection has focused on cream-skimming by private MA plans. These papers generally find that MA plans appear able to direct high-cost beneficiaries to the public, FFS Medicare pool, resulting in overpayments to MA plans. ${ }^{3}$ But this channel of risk-selection is not available to private plans in settings such as the ACA exchanges or MMC that do not offer a public FFS option. Similarly, many papers have found that without guaranteed-issue or community-rating mandates, private plans risk-select by simply denying high-cost enrollees

\footnotetext{
${ }^{1}$ See http://www.medicaid.gov/Medicaid-CHIP-Program-Information/By-Topics/Data-andSystems/Downloads/2011-Medicaid-MC-Enrollment-Report.pdf. In 2011, MMC accounted for 74 percent of all Medicaid enrollees.

${ }^{2}$ The proposal was known as Medicare Premium Support and failed in the Senate.

${ }^{3}$ See, e.g., Langwell and Hadley (1989), Physician Payment Review Commission (1997), Mello et al. (2003) and Batata (2004).
} 
or charging them higher premiums. ${ }^{4}$ But ACA exchange regulations essentially eliminate this possibility, and MMC plans must accept any eligible enrollee at the same premium (\$0). ${ }^{5}$ By 2019, via the exchanges and MMC, nearly sixty million Americans will be covered through this model of strictly private provision of public insurance, yet past work can give only limited guidance as to whether they will face risk-selection by insurers. ${ }^{6}$

We present a simple model of insurer incentives that illustrates how risk-selection can still occur in these new "exchange" settings - i.e., where the government finances capitated private plans, mandates guaranteed issue and community rating, but does not itself administer a public FFS plan. We then test the model's predictions using Texas' switch from Medicaid FFS to MMC for pregnant women and infants. Importantly, our model assumes that enrollees always have the choice of at least two private plans, a condition met in our data, generally met by state MMC programs and widely expected (indeed, promised) to be met in the ACA exchanges. $^{7}$ As in Hart et al. (1997), we also assume that the state cannot write complete contracts with insurers and thus some scope remains for them to adjust quality of care across enrollees. ${ }^{8}$ In fact, Texas explicitly encourages MMC plans to use their discretion to tailor many benefits individually.

Each period, profit-maximizing plans choose the level of care to provide to high- and lowcost patients (i.e., those whose expected costs are above and below the capitation payment,

\footnotetext{
${ }^{4}$ See Baicker and Dow (2009), for example, and citations therein.

${ }^{5} \mathrm{ACA}$ insurers are subject to guaranteed issue but may modestly adjust premiums for age and smoking status.

${ }^{6}$ See http://www.cbo.gov/sites/default/files/cbofiles/attachments/43472-07-24-2012CoverageEstimates.pdf, Table 3. CBO estimates that by 2019, 25 million individuals will be on exchanges and 43 million in Medicaid. As MMC currently accounts for 74 percent of all Medicaid enrollees (see footnote 1), we estimate that $0.74 * 43=32$ million will be on MMC. This figure is likely an underestimate as the MMC share of Medicaid enrollees has been steadily growing and will likely exceed 74 percent by 2019. All CBO enrollment projections reflect the June 2012 Supreme Court decision limiting the Medicaid expansion.

${ }^{7}$ See http://kaiserfamilyfoundation.files.wordpress.com/2013/01/8046-02.pdf, p. 2, on the prevalence of multiple plans in state MMC programs. Unfortunately, the authors write that "generally" enrollees have a choice of at least two plans, but do not give an exact share. Regarding the ACA exchanges, the Obama Administration has claimed that, based on current data, 90 percent of exchange enrollees will have the choice of at least five insurers: http://www. washingtonpost.com/blogs/wonkblog/wp/2013/05/30/areobamacares-exchanges-competitive-heres-what-the-experts-say/?wprss=rss_ezra-klein.

${ }^{8}$ Given that insurers must approve providers' charges, this adjustment in care can be directly passed down to providers.
} 
respectively). The probability that a patient returns to the same plan in the following period (e.g., in our context of Medicaid births, that she chooses the same plan for her child's later care or for her next pregnancy) increases with the level of care. Consequently, plans have an incentive to retain low-cost, profitable patients and thus provide them with greater levels of care relative to high-cost patients. By contrast, plans balance two competing incentives in treating a high-cost, unprofitable patient - although reducing the level of care may worsen her outcomes and increase costs in the current period, it will also encourage her to switch to a competitor in the next period. Unlike many models of adverse selection, plans in our framework need not be able to predict the costs of enrollees ex-ante or devise a menu of services that encourage the healthy to self-select (though they may also engage in such tactics as well). Instead, they can learn about patient costs and profitability over time and adjust quality of care accordingly based on whether they wish to retain the patient.

Our model has three main predictions that we test in the context of MMC. First, relative to FFS, MMC will lead to improved care for healthy, low-cost pregnant women and infants and worse care for unhealthy, high-cost pregnant women and infants. Second, as a result of the changes in care, health disparities between healthy and unhealthy infants will grow under MMC. Third, birth rates from high-cost groups will fall, either because, as suggested in past work, mothers react to diminished care and outcomes by reducing fertility or because plans specifically discourage births from unprofitable groups. ${ }^{9}$

To test these predictions, we require, first, a setting in which health care provision switches from FFS to capitation in a quasi-experimental manner, and, second, groups of enrollees who we, as researchers, can identify ex-ante as having different baseline health (and thus expected costs). We argue that Texas' county-by-county transition from FFS to MMC is a suitable experiment and focus on changes in outcomes and care between blacks and Hispanics. In Texas, blacks and Hispanics make up the large majority of Medicaid births, and, as we document in our empirical analysis, experience vastly different health outcomes. For

\footnotetext{
${ }^{9}$ On the connection between fertility and health care quality, see, e.g., Albanesi and Olivetti (2010), which we discuss later in the paper.
} 
example, mortality, low birth weight and other adverse birth outcomes are nearly twice as common among black relative to Hispanic births. ${ }^{10}$ These disparities translate into enormous differences in costs and profits - in Texas hospital discharge data, black infants have charges over eighty percent greater than Hispanics, but MMC plans receive the same capitation payment for the two groups.

Having identified our ex-ante high- and low-costs groups, we use birth records to explore how their outcomes change after a county switches to MMC. As predicted, black infant mortality rates significantly increase, while Hispanic rates significantly decrease, causing the black-Hispanic mortality gap to grow by 42 percent. The black-Hispanic low-birth-weight and pre-term-birth gaps also increase significantly. While large, our mortality effects are consistent with past work on the elasticity of infant mortality with respect to quality of care, as we discuss later.

Along almost all our measures of the quality of pre-natal care, Hispanics experience improvements relative to blacks, again as predicted. Interestingly, for blacks, MMC leads to a significant increase in the share of mothers who receive their pre-natal care at public clinics (generally meant for the uninsured) as opposed to doctors' offices.

Finally, given that insurers find it unprofitable to cover them and provide them with worse care, is there a change in birth rates among high-cost mothers after MMC? We document a significant decrease in black birth rates after a county switches to MMC. Increased abortions appear to account for a significant share of the effect, though data limitations prevent us from making a more definitive assessment of the role of abortions versus conceptions. In summary, under MMC, infants whose costs are likely to exceed the capitation payment die more frequently, experience worse health outcomes, receive diminished care, or are not born at all.

We believe our paper makes several contributions. First, it is the only paper, to our knowledge, to model risk-selection incentives in public "exchange" settings - where the gov-

\footnotetext{
${ }^{10}$ This black-Hispanic gap in health has also been widely documented in other settings. We review this evidence in Section 3.
} 
ernment regulates and finances competing, private plans but does not itself directly insure individuals - and to provide empirical evidence consistent with risk-selection in one such setting, MMC. When viewed dynamically, the possibility a client can switch plans means competing plans under capitation are not in fact true residual claimants on their patients' future costs and thus under-provide care to high-cost patients. In settings like Medicare with both private capitated plans and a public FFS option, the government bears the cost of riskselection in the form of overpayments to private plans; in exchange settings, by contrast, this cost is borne by enrollees with costs above the capitation payment.

Second, while the comparison is not often made, the ACA exchanges will mirror MMC in many ways and thus our results have implications for health reform. In addition to the similarities already noted, since the ACA exchange subsidies are generally unavailable to those with employer insurance, there will likely be substantial "churn" in the exchange population as people come and go based on their outside options (as in Medicaid). As such, the data-collection necessary for effective risk-adjustment in both contexts is difficult, and in fact few states attempt to adjust MMC capitation payments based on ex-ante health conditions. ${ }^{11}$ We discuss additional challenges common to both settings in the conclusion.

Third, our paper further enriches the current understanding of incentives under MMC, which by 2019 will serve as the primary insurer for roughly 32 million individuals (ten percent of the U.S. population) and is thus of interest in its own right. ${ }^{12}$ Two important papers have made use of the county-by-county switch from FFS to MMC in California, the same empirical strategy that we adopt for Texas. Duggan (2004) finds MMC increased costs in California, which he attributes to competing MMC plans' limited ability to negotiate favorable rates with providers relative to a consolidated FFS system. ${ }^{13}$ Aizer et al. (2007) note that capitation may create incentives to cut costs below the socially-optimal level, and indeed

\footnotetext{
${ }^{11}$ See Winkelman and Damler (2007). They find that only 13 states have implemented MMC riskadjustment or are considering it. Also see Weiner et al. (2012) for a review of issues related to risk-selection in the ACA insurance exchanges.

${ }^{12}$ See footnote 6 for the 32 million figure.

${ }^{13}$ Duggan and Hayford (2011) find supporting evidence that MMC increased costs relative to Medicaid FFS nationally using state panel data.
} 
find that pre-natal care and birth outcomes deteriorate under MMC in California. ${ }^{14}$ Neither paper finds evidence of risk-selection in California. As we discuss later, this discrepancy in results between Texas and California is consistent with differences in MMC program details between the two states. Thus, comparing our results with past work can help illustrate the tradeoffs involved in MMC program design.

Fourth, this paper finds results along a new margin - where pre-natal care is receivedthat suggests cost-shifting on the part of MMC plans. That women on MMC would turn to clinics meant for the uninsured suggests that plans may be directing their enrollees to free care instead of covering these costs themselves. In this sense, any savings under MMC are partially offset (or cost increases understated) by cost-shifting toward other safety-net programs, an example of the potential substitutability across social-welfare programs discussed by Borghans et al. (2012).

The remainder of the paper is organized as follows. Section 2 describes the transition to MMC in Texas and, in particular, documents the wide discretion that plans have in denying certain benefits to enrollees, adding plausibility to our thesis that they have the scope to improve care for profitable enrollees at the expense of unprofitable ones. Section 3 presents a simple dynamic-programming model of plans' incentives under MMC and lays out our predictions of how the transition from FFS to MMC will affect birth outcomes, quality of care, and birth rates for high-cost (black) and low-cost (Hispanic) groups. Section 4 describes our main data sources and empirical strategy. Section 5 presents the results on birth outcomes and quality of care. Section 6 presents the results on birth rates. Section 7 concludes by discussing welfare and policy implications and recommending areas for future work.

\footnotetext{
${ }^{14}$ There is an earlier literature on the effect of MMC on pre-natal care and birth outcomes on which we do not focus. Findings from these papers are mixed perhaps because many rely on cross-sectional comparisons and pre/post analyses without comparison groups (see Kaestner et al., 2002 for an overview). Such research designs may suffer from omitted variables bias due to individual selection into managed care or concurrent macroeconomic trends.
} 


\section{Background on Medicaid and the Transition to MMC in Texas}

After experimenting with a small managed care pilot program in four counties, the Texas legislature voted in 1995 to begin a staggered, state-wide shift from traditional Medicaid FFS to Medicaid managed care. The Texas Health and Human Services Commission (HHSC) set the order in which counties would switch. According to HHSC officials, small urban areas switched first because they tended to have well-established healthcare provider networks and it would be easier to work out transitional problems in smaller urban areas as opposed to the largest ones. Larger urban counties switched next, with rural counties switching only in 2012. As our key identifying assumption depends on the timing of the roll-out being uncorrelated with time-varying county characteristics, it is reassuring that the roll-out schedule was set by a central office and not negotiated by individual counties. Appendix Table 1 provides more details on the timing of the roll-out for each county. The percentage of the Texas Medicaid population enrolled in the managed care program (called State of Texas Access Reform, or STAR) increased from 2.9 in 1994 to 70.8 in 2009.

Participation in managed care among Medicaid enrollees is mandatory following MMC implementation in each county. Enrollees always have at least two plans in their county from which to choose, and are randomly assigned to one if they do not choose a plan by a given deadline after their county's switch to MMC. ${ }^{15}$ In Texas, as in almost all states, pregnant women and infants under one year of age are eligible for Medicaid if their family incomes fall under 185 percent of the federal poverty line (FPL). While older children face somewhat stricter Medicaid eligibility limits (133 percent of FPL for ages 1-5 and 100 percent of FPL for ages 6-18), adult women are essentially only eligible when pregnant.

Insurance providers receive a capitation payment for each enrollee based on historical Medicaid costs in the locality. For every woman who gives birth, plans receive a Delivery Supplementary Payment and a newborn premium, which are unadjusted outside of these

\footnotetext{
${ }^{15}$ In the rare cases when a Medicaid-eligible woman shows up at the hospital to deliver without having already chosen an MMC plan, she is randomly assigned a plan to cover the cost of the delivery and care of the infant.
} 
geographical averages. Because of the supplementary capitation payments associated with delivery and newborns, MMC does not discourage pregnancy per se, but high-cost births will cost far more than these fixed supplementary capitation payments and thus represent a large loss to plans. When we asked the HHSC about whether these basic capitation payments also applied to very high-cost births (by contrast, California creates a "carve-out" for high-cost Medicaid births and returns them to FFS-type reimbursement), we were told that plans would simply make up these losses on profits from low-cost births: "This average [capitation payment] does include the higher cost deliveries and yes, it would under-pay for those but then again it overpays for others to make up for it." 16

A final, important point about Texas MMC is that plans are encouraged to tailor benefits for each beneficiary. As noted in Texas HHSC Medicaid documentation:

Value-added services are additional health care services that an MCO [managed care organization] voluntarily elects to provide to its clients at no additional cost to the state. MCOs offer value-added services to attract clients to sign up with them, including adult dental services and diapers for newborns. Additional services may be offered to clients on a case-by-case basis at the discretion of the $M C O$ [emphasis added]. ${ }^{17}$

Plans thus have discretion to deny services to some enrollees while providing them to others. One optional service the documentation specifically mentions is post-natal in-home follow-up care, though the above quote suggests extremely wide latitude for other services as well. As our model in the next section depends on plans being able to improve services for low-cost patients at the expense of high-cost patients, documenting plan discretion lends plausibility to our hypothesis.

\section{Formalizing and quantifying incentives under $\mathrm{MMC}$}

We first lay out a simple model of incentives under MMC versus FFS that generates predictions about how care will diverge for low- and high-cost groups under the two regimes. We then quantify the empirical importance of cost heterogeneity among Texas infants.

\footnotetext{
${ }^{16}$ Email correspondence with the chief actuary for HHSC (March 30, 2012).

${ }^{17}$ See http://www.hhsc.state.tx.us/medicaid/reports/PB8/PDF/Chp-6.pdf, p. 6-7.
} 


\subsection{Modeling incentives under MMC versus FFS}

Consider two types of patients, healthy $(H)$ and sick $(S)$. Patient types are fixed over time. There are two types of costs that plans incur: those associated with preventive care $\theta$ and those associated with outcomes $c_{i}(\theta)$, where $c$ varies by patient type. ${ }^{18}$ For simplicity, let $c_{H}(\theta)=c(\theta)$ and $c_{S}(\theta)=c(\theta)+\alpha$, with $c^{\prime}<0$ and $c^{\prime \prime}>0$, so the returns to preventive care are the same across patient type. We do not distinguish between mothers and children and combine costs for both (so healthy mothers produce healthy infants).

Incentives under MMC. Under MMC, there are at least two plans from which patients can choose. Plans receive a capitation payment $p$ regardless of patient type. Plans face a dynamic problem - how they treat a patient today determines whether she will return in the next period. In our context, "returning the next period" can either mean that the mother continues using this plan for the infant's later health care needs or that she returns to this plan the next time she is pregnant (and thus eligible for Medicaid herself). Let $\lambda(\theta)$ be the probability a patient choses the same plan in the next period, which is increasing concavely in the care she receives in the current period, so $\lambda^{\prime}>0$ and $\lambda^{\prime \prime}<0$. We scale down this probability by a discount factor $\delta$ to reflect the fact that she may exit the Medicaid program (e.g., no longer meet the income test) and to ensure a finite stream of expected profits.

We assume that plans can quickly learn patient type after a mother enrolls. First, they might form a reasonable estimate based on basic observables such as age and race. Second, in an initial check-up, information such as BMI, blood-pressure, and health history will be gained. Third, diagnostic procedures throughout the pregnancy may reveal even more detailed information. We thus assume that patient type is observable to the plan at the point they are making much of their decisions about approving pre- and post-natal care.

Knowing patient type, each plan solves the following dynamic maximization problems:

\footnotetext{
${ }^{18} \mathrm{As}$ both these costs are direct functions of $\theta$ we could instead formulate the model in terms of a total cost function, but splitting costs in this manner aids with intuition and maps more closely to the empirical results.
} 


$$
\begin{aligned}
& V_{t}^{H}=\max _{\theta}\left\{p-\theta-c(\theta)+\delta \lambda(\theta) V_{t+1}^{H}\right\} \quad[\text { Healthy }] \\
& V_{t}^{S}=\max _{\theta}\left\{p-\theta-c(\theta)-\alpha+\delta \lambda(\theta) V_{t+1}^{H}\right\} \quad[\text { Sick }]
\end{aligned}
$$

Because for all $\theta, p-\theta-c(\theta)$, the flow payoff from covering type $H$, is greater than $p-\theta-$ $c(\theta)-\alpha$, the flow payoffs of covering type $S$, it holds that $V_{t+1}^{H}>V_{t+1}^{S}$. Differentiating each of the above expressions with respect to $\theta$ yields the following first-order conditions:

$$
\begin{gathered}
1=-c^{\prime}(\theta)+\delta \lambda^{\prime}(\theta) V_{t+1}^{H} \quad[\text { Healthy }] \\
1=-c^{\prime}(\theta)+\delta \lambda^{\prime}(\theta) V_{t+1}^{S} \quad[\text { Sick }]
\end{gathered}
$$

For healthy patients, plans equate the marginal cost of an additional unit of $\theta$ (one) against two marginal benefits: that increasing $\theta$ decreases outcome costs -i.e., $-c^{\prime}(\theta)$ — while increasing the probability that the plan will enjoy the expected future profit stream-i.e., $\delta \lambda^{\prime}(\theta) V_{t+1}^{H}$. For sick patients, the incentives are the same, except that the continuation payoff $\delta \lambda^{\prime}(\theta) V_{t+1}^{S}$ is smaller than that associated with a healthy patient, or perhaps negative. Either way, $V_{t+1}^{H}>V_{t+1}^{S}$ and $c^{\prime \prime}>0$ and $\lambda^{\prime \prime}<0$, so it must be that $\theta_{H}^{M M C *}>\theta_{S}^{M M C *}$.

Incentives under FFS. For simplicity, we model providers under FFS as being completely indifferent to outcome $\operatorname{costs} c_{i}$-they merely send the bills back to the state. We assume that FFS providers get paid some reimbursement rate $\rho$ for $\theta$, and their cost of effort (or opportunity cost) is $e(\theta)$, which is increasing convexly in $\theta$. Thus, for each client they provide some standard amount of care that satisfies $\rho=e^{\prime}(\theta)$, and so $\theta_{H}^{F F S *}=\theta_{S}^{F F S *} \equiv \theta^{F F S *}$.

Predictions. The key result of the model is a divergence of health inputs $\theta$ for healthy and sick groups under MMC relative to FFS. That is:

$$
\left(\theta_{H}^{M M C *}-\theta_{S}^{M M C *}\right)-\left(\theta_{H}^{F F S *}-\theta_{S}^{F F S *}\right)>0 .
$$

Assuming that health inputs have the expected effect on health outcomes, we predict the 
same divergence in outcomes after the switch from FFS to MMC-outcomes for healthy clients improve while those for sick clients deteriorate.

Managed care plans under capitation have an incentive to compete for low-cost enrollees and appear unattractive to high-cost enrollees in the hope they will join a competing plan in the next period. For example, in our context, MMC plans would have an incentive to provide discretionary in-home visits (one of the "voluntary benefits" mentioned in the Texas Medicaid documentation) to clients whose future pregnancies have expected costs below the capitation payment, so as to retain them as clients. By contrast, they would want highcost clients to sign up with a competing plan during their next pregnancy and would thus ration such care. Moreover, they may make it more difficult for high-cost groups to enroll (e.g., demanding more detailed documentation proving eligibility). As such, we predict that outcomes for high-cost groups will deteriorate relative to low-cost groups.

Moreover, we hypothesize that the switch to MMC will have effects on birth composition via at least two channels. First, groups whose care diminishes under MMC may lower their fertility (either through lower conception rates or higher abortion rates) in response. Albanesi and Olivetti (2010) offer evidence that improved health care for pregnant women during the 1950s contributed to the Baby Boom. ${ }^{19}$ We do not model our birth-composition prediction as it is a straight-forward consequence of an increase in the effective price of childbearing for certain groups and a decrease for others. Second, if the continuation probability $\lambda$ is not very responsive to quality of care $\theta$ and thus mothers' inertia is high, then plans might differentially encourage birth control (which is covered under Medicaid) for high-cost mothers. As such, we will also test for whether birth rates from high-cost groups fall after MMC.

Caveats to the model. While the above framework is primarily meant to motivate the empirical work, some of its simplifications and assumptions deserve further discussion. First, we do not model plans' incentives to influence initial enrollment-mothers find themselves

\footnotetext{
${ }^{19}$ There is a small literature on whether Medicaid itself or similar programs that provide pre- or post-natal care are pro-natalist. As discussed by Lopoo and Raissian (2012), as Medicaid has generally provided both enhanced coverage for the costs related to child birth as well as access to birth control, it is hard to separate whether the enhanced coverage alone would be pro-natalist.
} 
in a certain plan and then make decisions about future enrollment based on the care they received in the plan. In fact, as in the model of Glazer and McGuire (2000), plans may design their benefits to deter sick individuals from enrolling ex-ante. Assuming that they do, it seems likely that they would still engage in the ex-post risk-selection activities we model after patient type is further revealed.

Second, we assume that utilization of care, health outcomes, and client retention all positively covary. It could instead be the case that utilization does not influence outcomes (e.g., if we are at the "flat of the curve," as in Fuchs, 2004), though, as previously noted, Aizer et al. found that MMC-induced reductions of care were large enough to affect mortality and other outcomes. Similarly, it could be that the aspects of health care that induce patient satisfaction and retention are not those that influence health outcomes. ${ }^{20}$ Our model implicitly assumes there is sufficient overlap between the aspects of care that positively influence birth outcomes and those that lead mothers to continue with the MMC plan.

Third, to replicate the MMC setting, consumers pay zero premiums in our model. Future work might generalize this framework to allow consumers to pay more for enhanced coverage, as in the ACA exchanges. Depending on the correlations between income, insurance demand, and health, we suspect that allowing variation in premiums can either increase or decrease risk-selection.

Finally, our model does not give predictions on average care or outcomes under FFS versus MMC. For example, if $\rho$ (the FFS reimbursement rate) is very low, then the level of care $\theta$ might increase for both high- and low-cost groups under MMC. While Aizer et al. (2007) found deleterious effects on average quality of care in California, predictions on average outcomes are outside our model. As such, welfare effects are not straightforward, an issue we return to in the conclusion.

\footnotetext{
${ }^{20} \mathrm{An}$ interesting example of an aspect of care that generates patient satisfaction but has no clear effects on outcomes is whether the race of the doctor and patient match. Past work on doctor-patient "raceconcordance" finds that it strongly influence patient satisfaction (LaVeist and Nuru-Jeter, 2002), modestly influences health care utilization (LaVeist et al., 2003) but has no clear relationship with patient outcomes (Meghani et al., 2009).
} 


\subsection{Quantifying these incentives}

To test our model, we as researchers need to identify two subgroups of the Medicaid population with substantially divergent health care costs. As we document in the next section, blacks and Hispanics account for nearly seventy percent of Medicaid births in Texas (and for each group, over half of births are covered by Medicaid) and here we show they have vastly different health care costs.

Table 1 compares initial hospital charges for black and Hispanic births using 1999-2004 discharge data, controlling for county and year effects (as capitation payments are adjusted in this manner, though these controls have only a modest effect). ${ }^{21}$ Black newborns incur charges 81 percent greater than do their Hispanic counterparts, or, in absolute terms, an additional $\$ 4,218$ (col. 1). ${ }^{22}$ This absolute difference in initial hospital changes substantially understates the cost differences of black and Hispanic infants, as the elevated medical costs of at-risk births persist well beyond the initial hospital stay. ${ }^{23}$

The differences in costs associated with the mother are also substantial, with black mothers incurring 21 percent greater costs than Hispanics (col. 2). This cost gap is not driven by differences in mothers' ages (col. 3), the only relevant individual-level covariate we have in the discharge data. ${ }^{24}$

Figures 1(a) and 1(b) show the raw (unadjusted for county and year) difference in black and Hispanic births by percentile of the cost distribution. The black-Hispanic cost differences for newborns are positive at every centile, and the median difference is roughly $\$ 250$. We

\footnotetext{
${ }^{21}$ Unfortunately, discharge data with county identifiers are only available from the third-quarter of 1999 onward, and as such we cannot use it to compare outcomes before and after a county switched to MMC, since our last group of counties switch in January 1999. Consequently, in light of the results in Section 6 the cost differences from the discharge data that we report in Table 1 might be viewed as lower bounds, as plans may have already discouraged the most high-cost black births by 1999 .

${ }^{22}$ Hospital charge data are imperfect measures of the final cost to the insurer as plans negotiate discounts from providers. However, these discounts should not vary by demographic groups, so the comparisons in Table 1 give a good approximation of proportional cost differences.

${ }^{23}$ See, e.g., Tommiska et al. (2003) and McCormick et al. (1991).

${ }^{24}$ As we cannot link mothers to infants in these data, we cannot control for age-of-mother in the infant regressions in col. (1). Obviously, all newborns are the same age, so we cannot adjust for their own ages as we do for mothers.
} 
censor at the $95^{\text {th }}$ percentile $(\$ 8,452)$ as otherwise the graph is extremely compressed: the difference at the $99^{\text {th }}$ percentile is $\$ 76,341$. The differences in delivery charges associated with the mother are relatively constant for all percentiles, outside of some noise in the extreme right tail.

While we focus on the cost differences between blacks and Hispanics, differences by mother's age are also significant. While we cannot link mothers and newborns so cannot split newborn costs by the age of the mother, Table 1 shows that black and Hispanic mothers age 35 and older have delivery costs 15 percent greater and 14 percent greater than their younger counterparts, respectively (see cols. 4 and 5). In our birth certificate data that we describe in the next section, among black and Hispanic mothers the rates of pre-term and low-birth-weight are roughly thirty percent higher for those above age 35 . As such, births to older mothers represent a small but expensive subset of Medicaid births that plans would have an incentive to avoid. However, given that older mothers are unlikely to have a future birth, plans may be less worried about these unprofitable clients returning in future periods. For this reason, the empirical work generally focuses on differences by race, though we will show some results by mothers' age as well.

Before moving on to the empirical work, we emphasize two points. First, the large cost differences between blacks and Hispanics that we document are completely in line with past work on differences in birth outcomes. Hispanic infants in the U.S. are remarkably healthy, and in fact researchers have coined the term "Hispanic paradox" to describe the fact that despite socio-economic deprivation comparable to blacks, they in fact have birth outcomes (and, while less relevant for us, adult health outcomes) equal to or better than non-Hispanic whites. $^{25}$ Our main contribution in this section is to show that these large differences in health outcomes translate into equally large differences in initial hospitalization costs, the metric relevant to plans. We generally take the cost differences between blacks and Hispanics

\footnotetext{
${ }^{25}$ See, for example, Leslie et al. (2003), Haywood L Brown and Howard (2007), Alexander et al. (2003), and Dominguez (2008).
} 
as given, though briefly review potential explanations in the footnote below. ${ }^{26}$

Second, neither the model nor the empirical results that follow show that plans specifically discriminate against African-Americans. Rather, our model predicts that plans will improve the care of low-cost enrollees at the expense of high-cost enrollees, and to test this prediction we, as researchers, need to use a proxy (race) for ex-ante differences in expected medical costs. Plans themselves may use these proxies as well, or, because they have access to actual cost data throughout the pregnancy, may not need to use the proxies that we do.

\section{Data and empirical strategy}

\subsection{Main data source}

Our main source of data is the universe of birth records from the Texas Department of State Health Services (DSHS). These data contain detailed information on the child's exact birth date, birth outcomes, medical procedures, maternal demographics and health, and the mother's county of residence. Using recorded information on each child's birth date and gestation length, we calculate an approximate conception date for each observation. We merge the birth records data to data on the timing of MMC implementation by the mother's county of residence.

As Appendix Table 1 documents, counties switched from FFS to MMC between 1993 and 2006. We drop the four pilot counties that switched in 1993 as we could not determine when the pilot period ended. Since much of the focus of our analysis is on racial differences in birth outcomes and the racial composition of births, we do not analyze the January 2006 switch

\footnotetext{
${ }^{26}$ Our reading of the literature suggests that the Hispanic paradox is best explained by the superiority of diet and other health habits in Latin American countries relative to the U.S. (tellingly, these advantage appear to dissipate slightly in the second generation with assimilation, see Guendelman and Abrams, 1995). Another explanation is the "healthy migrant effect" - that only the healthier members of a home country choose to migrate - though Rubalcava et al. (2008) find only weak evidence that Mexicans who move to the US are healthier than their counterparts who remain. We do not agree with the claim that the Hispanic paradox is a statistical illusion driven by so-called "salmon bias" - that immigrants wish to return to their home country to die and thus are rendered "statically immortal" in U.S. vital statistics data. First, salmon-bias cannot explain differences in birth outcomes. Second, Abraido-Lanza et al. (1999) shows that the Hispanic paradox exists for Cuban immigrants (who, for political reasons, almost never return to their home country) and Puerto Rican immigrants (deaths in Puerto Rico are recorded in U.S. vital statistics data).
} 
into MMC as many Texas counties were affected by an influx of black refugees following Hurricane Katrina in September of $2005 .^{27}$ Therefore, we limit our sample of analysis to conceptions by mothers residing in Texas between January 1993 and December 2001, allowing for roughly three years before the first MMC switch (in December 1995) and three years after the last MMC switch (in January 1999). Finally, we drop the small number of birth records with missing information on gestation, parity, mother's age, mother's race/ethnicity, and mother's marital status. These sample restrictions leave us with 2,814,681 observations in our main analysis sample.

In Table 2, we present summary statistics for several demographic subsets of mothers. Black and Hispanic mothers are slightly younger than average, and considerably younger than married non-Hispanic white mothers. Pre-natal care measures are substantially different for minorities and non-Hispanic whites. Blacks (75 percent) and Hispanics (71 percent) are less likely to begin pre-natal care in the first trimester, relative to married whites (90 percent). Whereas less than four percent of married whites receive their pre-natal care in public clinics, 13 and 19 percent of blacks and Hispanics do, respectively.

Differences in birth outcomes are consistent with the large differences in hospital charges we presented earlier. Black rates of low-birth-weight, pre-term delivery and child death are, respectively, 90 percent, 56 percent and 88 percent greater than the corresponding rates for Hispanics, echoing the roughly 80-percent newborn cost differences we found in the discharge data. In fact, birth outcomes for all Hispanics (col. 3) are comparable to birth outcomes for married whites (col. 4), consistent with the "Hispanic paradox" noted earlier.

\subsection{Medicaid coverage}

One variable not included in Table 2 is Medicaid status, as Texas only included it on the birth certificate in 2005. However, Medicaid status is actually a problematic variable in the context

\footnotetext{
${ }^{27}$ Results are very similar when we do use the longer sample period and treat the 2006 transition as we do the earlier transitions, and in fact earlier versions of the paper included them before we realized Katrina could contaminate our results. It seems prudent to exclude this transition, however, as several of the counties that switch in 2006 are close to the Louisiana border.
} 
of studying MMC because privatizing Medicaid has the effect of making enrollees or providers incorrectly record the birth as being covered by a private insurer or by "other/unknown" source, a possibility hypothesized by Aizer et al. (2007).

Indeed, we find that this effect is empirically important when we examine Medicaid status for conceptions in 2004-2005 versus 2007-2008 in the counties that privatized in 2006. In the earlier period, 64.7 percent of births in these counties were recorded as covered by Medicaid, compared to 49.9 percent in the later period, whereas other counties in fact saw a small increase. Such a large and sudden decrease is inconsistent with declining fertility preferences among the Medicaid population in these particular counties but not others. It instead points to this mistaken recording of coverage and suggests that the Medicaid share from the birthcertificate data should be "grossed" up by roughly $1.3(64.7 / 49.9)$. Similarly, in 2005, the official count of Medicaid births from the Texas DHHS is 1.3 times the count in the birth certificate data. $^{28}$ As such, in Appendix Table 2 we gross up by 1.3 the share of Medicaid births in the birth certificate data to estimate the Medicaid share of births for selected groups conceived in 2004 (and born in 2005). This correction is of course rough, as different groups might differentially misreport Medicaid coverage under MMC.

Appendix Table 2 reflects the high share of Medicaid-covered births in Texas (in the 2000s, it typically ranked in the top six to eight states in this category, reflecting its relatively low rates of private insurance coverage). ${ }^{29}$ The majority of black and Hispanic births are covered by Medicaid, and these rates are just under half even among married mothers. Moreover, blacks and Hispanics account for 69 percent of reported Medicaid births. ${ }^{30}$ The Medicaid share for married white births is roughly a third of that same share for all blacks and Hispanics, and we will often use these births in placebo tests. ${ }^{31}$

\footnotetext{
${ }^{28}$ See http://www.hhsc.state.tx.us/medicaid/reports/PB8/PDF/Chp-4.pdf, p. 4-15. The official count indicates that 54 percent of births are covered by Medicaid, whereas our birth certificate data indicate 41 percent.

${ }^{29}$ See http://www. statehealthfacts.org/comparemaptable.jsp?yr=58\&typ=2\&ind=223\&cat=4\&sub= 57.

${ }^{30}$ From Appendix Table $2:(0.791 * 29262+0.584 * 133756) /(0.539 * 273471)=0.687$.

${ }^{31}$ We also have educational attainment in the births data and we could conceivably use it in the creation of placebo groups, but we are uncertain of its accuracy. For example, even among women old enough to have
} 


\subsection{Empirical Design}

We exploit variation in the timing of the roll-out of MMC across counties to create an event-study design, as in Duggan (2004) and Aizer et al. (2007). To ease the computational burden, we generally collapse data into county/conception-month cells and weight by cell size (equivalent to estimating the corresponding individual-level regression with no individuallevel controls).

Our estimating equation thus takes the form:

$$
Y_{y m c}=\beta M M C_{y m c}+\Lambda^{\prime} W_{y m c}+\mu_{c}+\gamma_{y}+\nu_{m}+\mu_{c} * t+\epsilon_{y m c}
$$

for births in county $c$, conceived in year $y$, month $m$. $Y_{y m c}$ is a birth outcome or demographic characteristic of interest, such as mortality, birth weight or gestation length. $M M C_{y m c}$ indicates that the conception occurred after MMC rollout in county $c . W_{y c}$ is a set of county-year specific controls including population, average income, and the unemployment rate. $\mu_{c}$ are

county fixed effects, $\gamma_{y}$ are conception-year fixed effects, $\nu_{m}$ are conception-month fixed effects, $\mu_{c} * t$ are county-specific linear time trends (to follow Aizer et al.), and $\epsilon_{y m c}$ is the error term, which we cluster by county. The key coefficient is $\beta$, which measures the effect of being conceived under MMC on the outcome of interest. To avoid imposing constraints on coefficients, we estimate equations separately for blacks and Hispanics and then test whether $\beta^{\text {Black }}-\beta^{\text {Hisp }}$ is of the expected sign and statistically significant.

\section{Results on birth outcomes and quality of care}

In this section, we first present results on birth outcomes among Hispanic and black mothers after MMC roll-out. We then explore whether our results are driven by compositional changes or differences in the quality of care following MMC.

completed high school (age 24 and older, say), women without a high school degree have lower Medicaid rates than those with a high school degree but no college. However, when we use college-educated white women as a placebo group instead of married white women, the results are similar and are available upon request. Another reason we focus on marital status and not education is that the abortions data that we introduce in Section 6 does not include information on education. 


\section{$5.1 \quad$ Results on birth outcomes}

Table 3 compares changes in mortality for black and Hispanics after MMC. For this and all other tables in this section, each pair of columns presents first the estimate for blacks and then the estimate for Hispanics. Toward the bottom of the table, the "Diff/p-val" row shows in the odd-numbered columns the corresponding differences in the $M M C$ coefficients $\left(\beta^{\text {Black }}-\beta^{\text {Hispanic }}\right)$ and the even-numbered columns present the $p$-value associated with the test of equality across the two coefficients. ${ }^{32}$

Cols. (1) and (2) show that mortality - measured by whether a death certificate can be matched with the birth certificate - increases by 0.136 percentage points or $0.136 / 1.208=$ 11.3 percent among black mothers, while falling by 0.100 percentage points or $0.10 / 0.642=$ 15.6 percent among Hispanic mothers. Both effects are statistically significant. This 0.236 percentage-point (or 0.236/(1.208-0.642) $=41.7$ percent) increase in the black-Hispanic mortality gap is itself highly significant $(p<.001)$. Adding basic county-time controls for population, income and employment has no effect on the results (cols. 3 and 4). ${ }^{33}$ Cols. (5) and (6) show that for both groups, the magnitude of the effect increases (markedly so for blacks) when only unmarried mothers are included (though the smaller sample leads to the Hispanic result losing precision). The gap remains highly significant and indicates that, among births to unmarried mothers, the black-Hispanic mortality gap grows by $0.335 /(1.283-0.750)=62.9$ percent.

We display these results graphically by substituting the $M M C$ indicator in equation (1) with dummy variables for the 36 months before and after county MMC implementation (normalizing the month of implementation to zero) and plotting these coefficients in Figure 2. Consistent with the regression results, blacks show a positive shift in mortality for children

\footnotetext{
${ }^{32}$ We test equality using seemingly-unrelated regression in Stata, equivalent to running a single regression in which every covariate is interacted with a dummy variable for race.

${ }^{33}$ We use county-year data on per-capita income and population from the Regional Economic Information System (REIS), and unemployment data from the Local Area Unemployment Statistics (LAUS) of the Bureau of Labor Statistics. We interpolate to create monthly measures to avoid sharp jumps at the end of calendar years.
} 
conceived under MMC while Hispanics show a similarly marked, but negative, shift. For both, the shift is coincident with MMC's introduction in a county.

Table 4 shows results for other birth outcomes. Again, health significantly worsens for black infants (cols. 1, 3, 5, 7): incidence of low-birth-weight (defined, as in the medical literature, $<2,500$ grams), abnormal birth weight (as in the medical literature, $<2,500$ $\mathrm{g}$ or $>4,000 \mathrm{~g})$, prematurity and labor/delivery complications increase, by six, five, seven and sixteen percent, respectively. The corresponding black-Hispanic gaps for the first three indicators increase by 13, 39 and 22 percent, respectively. Both blacks and Hispanics see increases in birth complications - this rise is harder to interpret as it can indicate both increased maternal or fetal distress or more aggressive delivery procedures such as c-sections (note that the incidence of complications is roughly the same for married whites as for blacks in Table 2, suggesting it is not simply a correlate of bad outcomes). Finally, Appendix Table 3 cols (1) through (5) show that none of the outcomes in Tables 3 or 4 change for married whites after MMC.

Interestingly, we find larger movement in the black-Hispanic mortality gap than in the low-birth-weight or pre-term gap; Aizer et al. (2007) also find that MMC had larger impacts on mortality than on these intermediate measures (though of course they are looking at averages, not gaps between subgroups). Aizer et al.'s estimate of the effect of MMC on neonatal death (a fifty percent increase) is comparable to our estimate of the effect on the black-Hispanic mortality gap (a 42 percent increase). As such, our results are large, but not unrealistic.

Our results are consistent with blacks receiving relatively lower-quality care after MMC (as in our model), but also with negative changes in selection into birth for black infants versus Hispanics. Table 5 examines whether incidence of maternal risk-factors differentially change for blacks and Hispanics after MMC. Cols. (1) and (2) show that after MMC mothers in both groups are younger on average (a result we return to later); cols. (3) and (4) show they are both less likely to have diabetes or hypertension (though only Hispanics are significant); 
cols. (5) and (6) show blacks are less likely and Hispanics more likely to smoke (though neither result is significant on its own). Of the three outcomes, two (age and smoking) show statistically significant black-Hispanic divergences, both in the direction of blacks being relatively positively selected after MMC, suggesting the effect of MMC on the divergence of birth outcomes in Table 3 and 4 is understated.

Indeed, when we re-run regressions in Appendix Tables 4 and 5 for each of the birth outcome variables using individual-level data and controlling for all plausible pre-determined covariates on the birth certificate (see Table notes), each result grows slightly in magnitude for blacks, consistent with mild positive selection post-MMC. The sign of the change for Hispanics depends on the outcome variable, but in all cases is close to zero. Texas no longer provides researchers data with mother identifiers, so we cannot compare siblings, but given how stable the coefficients are with and without controls and the results on selection in Table 5 , we are confident that our birth-outcome results are not driven by selection. ${ }^{34}$

\subsection{Results on birth inputs}

The birth certificate data provide information on pre-natal care and procedures used at birth, though as Reichman and Schwartz-Soicher (2007) document, pre-natal care information on birth certificates (relying on mothers' recall) is less accurate than birth outcomes data. As many questions are about the procedures at the actual delivery or asked about the entire pregnancy (e.g., did you ever visit a public clinic for pre-natal care during your pregnancy), we generally define someone as "treated" by MMC if they were born, as opposed to conceived, under MMC.

Table 6 shows results for usage of the following procedures: fetal heart monitoring, ventilator, ultrasound and amniocentesis. The black-Hispanic differences are all in the expected direction and all but ventilator usage are statistically significant. Though the black-Hispanic divergence is not significant, the results on ventilator use are potentially interesting. As pre-

\footnotetext{
${ }^{34}$ It is also reassuring that Aizer et al. find that regressions with and without mother fixed effects yield similar results.
} 
term birth is an important predictor that an infant will need to be on a ventilator, given the results in Table 4 on pre-term births, standard protocol would have implied a large increase in ventilator use among blacks and a perhaps an insignificant decrease among Hispanics. While the implied result obtains for Hispanics, black infants see their ventilator use significantly fall despite their greater need for the intervention, suggesting diminished care. ${ }^{35}$

The relative decrease in fetal monitoring and the absolute decrease in ventilator use for blacks suggests that after MMC, black mothers gave birth in lower-quality hospitals. Indeed, Aizer et al. find that under MMC Medicaid births were less likely to take place in hospitals with a neonatal intensive care unit (where infants on ventilators would be admitted) and more likely to take place in hospitals with higher risk-adjusted infant mortality rates. While we do not have hospital identifiers in our data and thus cannot test whether hospital quality diverges for blacks and Hispanics after MMC, the results on birth procedures point in that direction.

Unlike Aizer et al., we do not find that MMC led to delays in the initiation of pre-natal care for either blacks or Hispanics (not shown). However, we find interesting patterns on where women receive pre-natal care, reported in Table 7. Especially among black mothers, the share who receive their pre-natal care at a public clinic substantially increases, while the share receiving it in a hospital or private office both decrease. The increase in the share turning to public clinics is striking - a 3.6 percentage-point, or 27 percent, increase. The effect for Hispanics is also positive, but smaller and not significant (col. 4).

Texas HHSC told us that these "public clinics" would include Planned Parenthood along with "clinics that serve the uninsured." The fact that black mothers would turn to these clinics at such higher rates after MMC is consistent with plans being slower to enroll them or providing them more limited care and access, as suggested by the discussion in Section 3. Alternatively, MMC plans may simply be directing clients to free clinics as a way to cut their costs regardless of the underlying cost or racial background of the clients. While the

\footnotetext{
${ }^{35}$ See http://www.nlm.nih.gov/medlineplus/ency/article/007240.htm on the recommended use of ventilators for premature infants, whose lungs are often insufficiently developed at birth.
} 
coefficient in the public clinics regression is not significant for Hispanics, it is positive and economically non-trivial, and for both blacks and Hispanics we see a fall in pre-natal care in hospitals. Of course, this cost-cutting is merely passing costs on to the state, counties and other parties who fund these clinics. If similar practices occur in other states, then the cost increases that Duggan (2004) attributes to MMC might in fact be understated.

Except for one outcome (ventilator use), there is no change in quality of care measures for married whites (see Appendix Table 6). Given that we examine in total thirteen outcomes using our married-white placebo group and this outcome is the only showing a significant effect, it could well be significant by chance.

In sum, our examination of results on birth outcomes, selection and care access indicate that widening health disparities between black and Hispanic births are likely driven by care, rather than selection. As documented in Section 2, MMC plans have vast discretion to tailor services on a case-by-case basis and appear to have directed more attention to lower-cost clients at the expense of higher-cost clients. It is worth noting that we cannot observe many inputs (e.g., the in-home visits noted in the Medicaid documentation) and these unobservables might also play a large role in the outcome divergences we document. However, the inputs we can observe generally move in the predicted direction and are consistent with a significant widening of black-Hispanic health disparities.

\section{Results on fertility}

Here we test whether births rates of high-cost groups fall after MMC, either because women respond to worse care and outcomes by reducing fertility or because plans actively discourage these women from having children so as to limit their exposure to unprofitable births.

\subsection{Main results}

Table 8 presents regression results based on equation (1) with the black share of births in a county-month now the outcome variable. In col. (1), this share falls by 0.196 percentage points, or 1.7 percent from the sample mean. As with the mortality results, the effect 
is concentrated among unmarried black births - col. (2) shows that the share of births to unmarried black mothers falls by 0.276 percentage points, or 3.95 percent. Col. (3) shows that this result is robust to adding the county-month controls for the unemployment rate, population and personal income.

The dependent variables so far in Table 8 is the ratio of black (or unmarried black) births to all births, and thus could conceivably be driven by an increase in non-black births. Col. (4) and (5) regress the log of births to black women and black unmarried women, respectively, and show that the ratio is indeed being driven by a decrease in the numerator of the ratios, with little effect on all other births (col. 6). ${ }^{36}$

Figure 3 (a) shows results graphically, again plotting coefficients from dummies corresponding to 36 months before and after a county switched to MMC. A decrease in level and break from trend coincident with MMC's introduction can be seen. Because of the rapid rise in the Hispanic share of births over our sample period (about 0.83 percentage points per year) and the resulting mechanical decrease in other groups' share, our results could be sensitive to how county time trends are specified. In fact, dropping country trends (subfigure b) or using quadratic trends (subfigure c) produces a more pronounced decrease in the black share of births (and the corresponding regression coefficients are of greater magnitude than that in col. 1 using linear trends, not shown), suggesting our choice of linear county time trends is conservative.

As a robustness check, we dropped each county individually to ensure that no single county was driving our results - in all cases, the coefficient in col. (1) remained negative and statistically significant (results available upon request). We also examined whether the "echo" of this birth composition result could be seen in 2005-2011 American Community Survey data as the children born during our sample grew older. We would expect this result to be much noisier, as we proxy county of birth with current county of residence, can only

\footnotetext{
${ }^{36}$ We restrict the sample in cols. (4) and (5) to those counties with at least one black unmarried birth in every month, to avoid having to take the $\log$ of zeros. These counties account for 87 percent of black unmarried births and 67 percent of all births.
} 
observe quarter instead of month of birth, and can only identify 24 counties as the ACS does not specify smaller counties for confidentiality reasons. Nonetheless, Appendix Figure 1 shows some evidence of a decrease in the black share of cohorts conceived after MMC (though the corresponding regression result is not quite significant at the ten-percent level, results available upon request).

Finally, we note that the decrease in black births is not a result of changing migration patterns among black Texans, either in response to MMC's introduction or merely in a manner coincidentally correlated with it. If our birth rate results were driven by entire families moving we should see enrollment for school-age black children decrease when a county switches to MMC. Using administrative data from the National Center for Education Statistics in Appendix Table 7, we find no such effect - the coefficient on MMC introduction is close to zero and switches signs depending on the specification.

\subsection{Exploring mechanisms for the fall in black births}

Miscarriages. As we have documented in the previous section, by many measures birth outcomes and pre-natal care deteriorate under MMC for black children, suggesting miscarriages could account for the "missing" black births. While we do not have data on miscarriages, past work has shown that male neonates are far more likely to miscarry. ${ }^{37}$ We thus hypothesize that if miscarriages were driving our results, we would see a corresponding decrease in the sex ratio among live births. Moreover, because the medical literature has shown that maternal stress during pregnancy decreases the sex ratio at birth, the male share of births may itself be of interest as it reflects maternal well-being during pregnancy. ${ }^{38}$

Table 9 suggests no significant decrease in the male share of births for either blacks or unmarried blacks (cols. 1 and 2), though in both cases the coefficient of interest is negative, as predicted. We show the graphical results as well in Figure 4(a) for unmarried black mothers.

\footnotetext{
${ }^{37}$ See Vatten and Skjrven (2004) and Byrne et al. (1987).

${ }^{38}$ This literature tends to exploit exogenous events such as earthquakes or terrorist attacks as well as more secular events such as business cycle employment variation. See, e.g., Fukuda et al. (1998), Catalano et al. (2005), and Catalano et al. (2006).
} 
There is perhaps a small break when MMC starts, though the results are noisy. While we have not been able to find existing research that would suggest a rough elasticity of the sex ratio with respect to the miscarriage probability, we suspect that given sample size and expected effect size, the test may be underpowered.

Interestingly, the male share of births to Hispanics increases (col. 3), significantly so for unmarried Hispanics (col. 4), and the difference in the male share between blacks and Hispanics is highly significant among unmarried mothers (not shown). Given the documented connection between the sex ratio at birth and maternal well-being during pregnancy, this result is consistent with the model's prediction of improved care and outcomes for low-cost mothers. And the graphical results in Figure 4(b) suggest that the break occurs at the time of MMC implementation.

Abortions. We examine abortion rates from 1998 to 2002, as individual-level abortion data has only been released consistently from 1998 onward. In these regressions, we consider someone as "treated" if they conceive after MMC or within three months of its introduction, since the large majority of abortions in Texas during our sample period occur two to three months after conception.

Given the shorter sample period, this analysis is obviously limited by being identified from a set of counties that all switch at the same time - only those counties that switch in 1999 contribute to the identification - as well as having a relatively short pre-period. Nonetheless, the results are rather striking. In col. (1) of Table 10, the abortion rate among blacks increases by 1.89 percentage points, or 6.7 percent from a sample mean of 27.9 percent. ${ }^{39}$ Cols. (2) and (3) show that this effect is driven by unmarried black mothers, consistent with our previous result that the fall in black birth rates is concentrated among unmarried women. Cols. (4) and (5) show, respectively, that the result is unchanged by starting the sample two months later (in case reporting in the first few months of 1998 was less reliable) and is

\footnotetext{
${ }^{39}$ Some readers have commented that the mean abortion rates in Table 10 appear too high. In fact, abortion rates in Texas during our sample period were slightly lower than the national average. In 1999, the ratio of abortions to births plus abortions was 18 percent in Texas, whereas the CDC reported that nationally that same ratio was 20.3 percent. See http://www.cdc.gov/mmwr/preview/mmwrhtml/ss5109a1.htm.
} 
smaller but still significant if county trends are dropped (in case the short pre-period leads to mis-estimated county trends). There is no effect for either Hispanic or Hispanic unmarried mothers (cols. 6 and 7) and no effect for white married mothers (Appendix Table 6, col. 7).

Re-estimating the main birth-composition result (col. 1 of Table 8) for the same conceptionmonths as in Table 10 suggests that abortion explains 37 percent of "missing" black births. While the short pre-period concerns us, if the effect for unmarried blacks is driven by, say, MMC counties differently improving their abortion reporting over the sample period, we would expect to see some increase as well among similar groups (married blacks, unmarried Hispanics). We thus conclude that abortion appears to be an important factor explaining the fall in black births.

In Texas, Medicaid cannot pay for clients' abortions. However, no restrictions exist on discussing abortion with Medicaid clients and MMC may contract with doctors who are more willing to discuss the option. ${ }^{40}$ In addition, it is also possible that women who are on the margin of aborting a pregnancy might be influenced by the initial interactions they have with their providers and insurers. Diminished quality and access to care may make mothers feel that the pregnancy will be a stressful and overwhelming experience, and we showed earlier that care appears diminished for black mothers under MMC.

The result on abortion rates may relate to the increases in pre-natal care provided by public health clinics discussed above, in two potentially reinforcing ways. On the one hand, as noted above, women who receive their pre-natal care at clinics instead of alternative settings may come into contact with providers and other clients who are more likely to suggest abortion as an option. On the other hand, the vast majority of abortions are performed at clinics (as opposed to a doctor's office or hospital), so if more mothers are considering abortion, their contact with clinics increases. ${ }^{41}$ Some who eventually decide against abortion

\footnotetext{
${ }^{40}$ In fact, in 2012 Governor Rick Perry made a failed attempt to impose such a restriction. See http://www.austinchronicle.com/blogs/news/2012-10-19/planned-parenthood-out-but-docscan-still-discuss-abortion-in-new-texas-womens-health-program/. While Perry failed in the attempt to restrict discussion of abortion, he succeeded in excluding Planned Parenthood from receiving funding through a Medicaid-waiver program.

${ }^{41}$ See Finer and Henshaw (2003). They report that 93 percent of abortions in 2000 were performed at
} 
may simply begin their pre-natal care at, say, the same Planned Parenthood clinic where they had received information about abortion.

\subsection{Do plans actively discourage high-cost births?}

While it is in plans interest to limit high-cost births, it could also be the case that the "missing" black infants are merely the result of MMC being better at providing access to contraception than FFS, and black mothers having had the greatest unmet demand under FFS. Though it is worth noting that Kearney and Levine (2009) find, nationally, when lowincome women are provided greater access to contraception, Hispanic births fall differentially, suggesting Hispanics, not blacks, have greater unmet demand for contraception. Moreover, the increase in black abortions suggest if anything a rise in unwanted black conceptions under MMC, inconsistent with greater access to contraception.

In addition, it is perhaps harder to argue that, within the groups most likely to be on Medicaid, higher-cost subgroups such as older mothers differentially had the greatest unmet demand for contraception under FFS. Decreases in births among high-cost subgroups might be seen instead as evidence of a more active role played by plans. Indeed, recall that in Table 5 we saw that the share of births to mothers over 35 fall significantly for both blacks and Hispanics (by eight and four percent, respectively). There is no such pattern for married whites (Appendix Table 3, col. 8).

In summary, after MMC, unprofitable births become rarer. Black births - nearly twice as costly as Hispanic births - fall significantly after MMC. And among black and Hispanics, births to older mothers also fall significantly. We suspect these results arise from some mix of high-cost mothers' limiting fertility in response to poor care and outcomes and plans differentially discouraging their births, but we do not have the ability to separate these two mechanisms.

Comparing our results with past work on California MMC nicely illustrates the classic trade-off between incentives for cost-control and risk-selection. As noted, California has lowerclinics. 
powered incentives, as expensive cases were "carved out" and passed back to the state. Aizer et al. credit the carve-out with reducing incentives for preventive care, thus leading to worse birth outcomes under MMC. As the state both paid capitation payments to plans and picked up the bill for some adverse outcomes, total costs went up (Duggan, 2004). However, neither paper finds evidence that high-cost births went "missing" after MMC or that health disparities widened, as we do. Thus, carving out high-cost births appears to diminish plans' incentive to reduce long-run costs through preventive care, but it also decreases the incentive to avoid or discourage high-cost births.

\section{Conclusion}

We develop a simple dynamic model of risk-selection in "exchange" settings - where the state finances and regulates competing, capitated private plans but does not itself administer a public FFS plan. Plans have incentives to retain healthy, low-cost patients, whereas they prefer their high-cost clients to switch to a competing insurer. As such, they improve care for the former group at the expense of the latter.

We test this prediction using the transition from FFS Medicaid to Medicaid managed care in Texas. Black infants in our data have nearly twice the incidence of serious health problems and are nearly twice as costly as Hispanics, and thus our model predicts their outcomes should diverge even further under MMC. We show that the black-Hispanic mortality, low birth weight and pre-term birth gaps increase by 42, 13 and 22 percent, respectively, after a county switches from FFS to MMC. Quality of pre-natal care and birth procedures generally improve for Hispanics relative to blacks and black birth rates fall substantially after MMC.

While our model makes sharp predictions on how care and outcomes diverge under MMC, it does not directly speak to overall welfare. Given the larger number of Hispanics in Texas, average birth outcomes do not decline despite significant deterioration among black infants. However, if society wishes to shrink health disparities, then MMC may be inferior to FFS as it transfers health resources away from a group with poor average health. As the returns 
to health investments are thought to be lower for the healthy than the sick (Grossman, 1972), such a transfer could lower total welfare. Finally, if health insurance is in part meant to smooth the utility consequences of ex-ante differences in health, then, relative to FFS, MMC's transferring of resources from the sick to the healthy weakens the insurance value of the Medicaid program.

The welfare effects of changes in birth composition are even more difficult to interpret. Given the challenges single-parent households face, that the decline in black births is driven by unmarried mothers could be seen as a positive effect of the reform. However, this view may be too narrow and the desirability of the result may depend on the mechanism-e.g., whether plans are merely supplying birth control to women with previously unmet demand or if they are actively discouraging births among mothers because of their expected costs.

Future work can hopefully make more progress toward pinning down underlying mechanisms than we have. In fact, this limitation is generally shared by the literature on riskselection: there is ample evidence that private, capitated plans often manage to avoid highcost enrollees, but almost no evidence on how they accomplish this selection. To our knowledge, there is only one audit study on risk-selection, Bauhoff (2012). He finds that even highly regulated private plans in the German health system are slower to enroll individuals who contact them from high-cost regions of the country. More work along these lines seems essential, especially in the U.S. context where the ACA will soon provide millions of individuals health coverage through private, capitated plans.

In our model, an inefficiency arises because plans want clients with costs above the capitation payment to switch to a competitor and thus reduce their care below the sociallyoptimal level. This result suggests that competition may undermine the underlying policy goal of capitation - instead of acting as the residual claimant on costs above or below the capitation payment and thus internalizing patients' future costs, plans attempt to pass on these costs to their competitor. This externality problem would not exist with a monopolistic insurer (though other problems associated with monopoly might arise). As all counties in 
Texas offer a choice between at least two competing MMC plans, we could not compare counties with and without competition, but future work might examine other MMC settings.

Introducing risk-adjustment could potentially address the risk-selection results we have presented, though, historically, governments have been reluctant to risk-adjust based on race. Adjusting based on past health conditions is very challenging in the MMC setting and, as previously noted, is rarely attempted. First, plans would have to submit some accounting of their clients' health conditions to the government, so "intensive" coding becomes a problem, as it is in Medicare Advantage and the Medicare Prospective Payment System. ${ }^{42}$ Second, while Medicare can calibrate a risk-adjustment formula by regressing enrollee costs on dummies for past health conditions using cost and claims data from its FFS pool, state governments under MMC typically do not have a public FFS option and thus will not have the cost and claims data that Medicare uses. Third, risk-adjustment formulae typically document existing health conditions using twelve months of pre-data, and use this information to forecast costs for the following twelve months. A stable client population - as in Medicare - is thus required, a challenge in Medicaid given the "churning" of the client base.

Each of these three challenges would seem to apply equally to the ACA state exchanges. Regulators will rely on insurers' accounting of client health conditions, and as there is no public FFS option they will not have their own cost and claims data. And as the exchanges serve those too rich for Medicaid but not so well off as to have employer insurance, their clients will likely come and go based on outside options - if their situation improves, then they will move into employer insurance; if their situation deteriorates, then they may need to switch to Medicaid.

With Medicaid Managed Care, the ACA exchanges, Medicare Part D and the prominence of Medicare premium-support proposals, the U.S. is moving rapidly toward providing public health insurance through a model of competing, capitated private insurance plans. Past work

\footnotetext{
${ }^{42}$ See the Center for Medicare and Medicaid Services on "intensive coding" among MA plans: http://www . cms.gov/Medicare/Health-Plans/MedicareAdvtgSpecRateStats/downloads/Advance2008. pdf. See Silverman and Skinner (2004) on provider "up-coding" practices after PPS.
} 
has identified challenges associated with this model, including the increase in costs that come with insurers losing monopsony bargaining power over providers and consumers' cognitive overload from choosing among a large set of options. ${ }^{43}$ Our work points to an additional concern arising from consumer choice - it tempts insurers to under-serve high-cost clients in the hope they will switch to a competitor. However, in most contexts consumer choice and competition are beneficial, and restricting choice among insurers all else equal has been found to significantly decrease consumer surplus. ${ }^{44}$ Given the direction of U.S. health policy, future work to better assess these trade-offs is of growing importance.

\section{References}

Abaluck, J. and Gruber, J. (2011). Choice Inconsistencies among the Elderly: Evidence from Plan Choice in the Medicare Part D Program. The American Economic Review, 101 (4), 1180-1210.

Abraido-Lanza, A. F., Dohrenwend, B. P., Ng-Mak, D. S. and Turner, J. B. (1999). The Latino Mortality Paradox: A Test of the "Salmon Bias" and Healthy Migrant Hypotheses. American Journal of Public Health, 89 (10), 1543-1548.

Aizer, A., Currie, J. and Moretti, E. (2007). Does Managed Care Hurt Health? Evidence from Medicaid Mothers. The Review of Economics and Statistics, 89 (3), 385-399.

Albanesi, S. and Olivetti, C. (2010). Maternal Health and the Baby Boom. Working Paper 16146, National Bureau of Economic Research.

Alexander, G. R., Kogan, M., Bader, D., Carlo, W., Allen, M. and Mor, J. (2003). US Birth Weight/Gestational Age-Specific Neonatal Mortality: 19951997 Rates for Whites, Hispanics, and Blacks. Pediatrics, 111 (1), e61-e66.

Baicker, K. and Dow, W. H. (2009). Risk Selection and Risk Adjustment: Improving Insurance in the Individual and Small Group Markets. Inquiry, 46 (2).

Batata, A. (2004). The Effect of HMOs on Fee-For-Service Health Care Expenditures: Evidence from Medicare Revisited. Journal of Health Economics, 23 (5), 951 - 963.

Bauhoff, S. (2012). Do health plans risk-select? An audit study on Germany's Social Health Insurance. Journal of Public Economics.

Borghans, L., Gielen, A. C. and Luttmer, E. F. (2012). Social Support Substitution and the Earnings Rebound: Evidence from a Regression Discontinuity in Disability Insurance Reform. Tech. rep., National Bureau of Economic Research.

\footnotetext{
${ }^{43}$ See Dafny et al. (2012) and Abaluck and Gruber (2011), respectively.

${ }^{44}$ See Dafny et al. (2013).
} 
Byrne, J., Warburton, D., Opitz, J. M. and Reynolds, J. F. (1987). Male Excess Among Anatomically Normal Fetuses in Spontaneous Abortions. American Journal of Medical Genetics, 26 (3), 605-611.

Catalano, R., Bruckner, T., Anderson, E. and Gould, J. (2005). Fetal Death Sex Ratios: A Test of the Economic Stress Hypothesis. International journal of Epidemiology, 34 (4), 944-948.

- - - Marks, A. and Eskenazi, B. (2006). Exogenous Shocks to the Human Sex Ratio: The Case of September 11, 2001 in New York City. Human Reproduction, 21 (12), 31273131.

Dafny, L., Duggan, M. and Ramanarayanan, S. (2012). Paying a Premium on Your Premium? Consolidation in the US Health Insurance Industry. The American Economic Review, 102 (2), 1161-1185.

- Ho, K. and Varela, M. (2013). Let Them Have Choice: Gains from Shifting Away from Employer-sponsored Health Insurance and Toward an Individual Exchange. American Economic Journal: Economic Policy, 5 (1), 32-58.

Dominguez, T. P. (2008). Race, Racism, and Racial Disparities in Adverse Birth Outcomes. Clinical obstetrics and gynecology, 51, 360-70.

DugGan, M. (2004). Does contracting out increase the efficiency of government programs? evidence from medicaid hmos. Journal of Public Economics, 88 (12), 2549-2572.

- and Hayford, T. (2011). Has the Shift to Managed Care Reduced Medicaid Expenditures? Evidence from State and Local-Level Mandates. Working Paper 17236, National Bureau of Economic Research.

Finer, L. B. and Henshaw, S. K. (2003). Abortion Incidence and Services in the United States in 2000. Perspectives on Sexual and Reproductive Health, 35 (1), 6-15.

Fuchs, V. R. (2004). More Variation in Use of Care, More Flat-of-the-Curve Medicine. Health Affairs, 23, VAR-104.

Fukuda, M., Fukuda, K., Shimizu, T. and Moller, H. (1998). Decline in Sex Ratio at Birth after Kobe Earthquake. Human Reproduction, 13 (8), 2321-2322.

Glazer, J. and MCGuire, T. G. (2000). Optimal Risk Adjustment in Markets with Adverse Selection: An Application to Managed Care. American Economic Review, 90 (4), 1055-1071.

Grossman, M. (1972). On The Concept of Health Capital and the Demand for Health. The Journal of Political Economy, 80 (2), 223-255.

Guendelman, S. and Abrams, B. (1995). Dietary Intake Among Mexican-American Women: Generational Differences and a Comparison with White Non-Hispanic Women. American Journal of Public Health, 85 (1), 20-25.

Hart, O., Shleifer, A. and Vishny, R. (1997). The Proper Scope of Government: Theory and an Application to Prisons*. Quarterly Journal of Economics, 112 (4), 1127-1161. 
Haywood L Brown, Y. J., Monique V Chireau and Howard, D. (2007). The "Hispanic Paradox": An Investigation of Racial Disparity in Pregnancy Outcomes at a Tertiary Care Medical Center. American Journal of Obstetrics and Gynecology, 197 (2), 197e1 $197 \mathrm{e} 9$.

Kaestner, R., Dubay, L. and Kenney, G. (2002). Medicaid Managed Care and Infant Health: A National Evaluation. Working Paper 8936, National Bureau of Economic Research.

Kearney, M. and Levine, P. (2009). Subsidized Contraception, Fertility, and Sexual Behavior. The Review of Economics and Statistics, 91 (1), 137-151.

Langwell, K. and Hadley, J. (1989). Evaluation of the Medicare Competition Demonstrations. Health Care Financing Review, 11 (2), 65-80.

LaVeist, T. A. and Nuru-Jeter, A. (2002). Is Doctor-Patient Race Concordance Associated with Greater Satisfaction with Care? Journal of Health and Social Behavior, pp. $296-306$.

—, - and Jones, K. E. (2003). The Association of Doctor-Patient Race Concordance with Health Services Utilization. Journal of Public Health Policy, pp. 312-323.

Leslie, J. C., Galvin, S. L., Diehl, S. J., Bennett, T. A. and Buescher, P. A. (2003). Infant Mortality, Low Birth Weight, and Prematurity among Hispanic, White, and African American Women in North Carolina. American Journal of Obstetrics and Gynecology, 188 (5), 1238 - 1240.

Lopoo, L. M. and Raissian, K. M. (2012). Natalist Policies in the United States. Journal of Policy Analysis and Management, 31 (4), 905-946.

McCormick, M. C., Bembaum, J. C., Eisenberg, J. M., Kustra, S. L. and Finnegan, E. (1991). Costs Incurred by Parents of Very Low Birth Weight Infants after the Initial Neonatal Hospitalization. Pediatrics, 88 (3), 533-541.

Meghani, S. H., Brooks, J. M., Gipson-Jones, T., Waite, R., Whitfield-Harris, L. and Deatrick, J. A. (2009). Patient-Provider Race-Concordance: Does it Matter in Improving Minority Patients Health Outcomes? Ethnicity $\&$ Health, 14 (1), 107-130.

Mello, M. M., Stearns, S. C., Norton, E. C. and Ricketts, T. C. (2003). Understanding Biased Selection in Medicare HMOs. Health Services Research, 38, 961-992(32).

Newhouse, J. (1996). Reimbursing Health Plans and Health Providers: Efficiency in Production versus Selection. Journal of Economic Literature, 34 (3), 1236-1263.

Physician Payment Review Commission (1997). Testimony of Gail R. Wilensky. Statement before the U.S. House of Rrepresentatives Subcommittee on Health. Comittee on Ways and Means, February 24, 1997.

Reichman, N. E. and Schwartz-Soicher, O. (2007). Accuracy of Birth Certificate Data by Risk Factors and Outcomes: Analysis of Data from New Jersey. American Journal of Obstetrics and Gynecology, 197 (1), 32-e1. 
Rubalcava, L. N., Teruel, G. M., Thomas, D. and Goldman, N. (2008). The Healthy Migrant Effect: New Findings From the Mexican Family Life Survey. Journal Information, 98 (1).

Silverman, E. and Skinner, J. (2004). Medicare Upcoding and Hospital Ownership. Journal of Health Economics, 23 (2), 369-389.

Tommiska, V., Tuominen, R. and Fellman, V. (2003). Economic Costs of Care in Extremely Low Birthweight Infants during the First 2 Years of Life*. Pediatric Critical Care Medicine, 4 (2), 157-163.

Vatten, L. J. and Skjrven, R. (2004). Offspring Sex and Pregnancy Outcome by Length of Gestation. Early Human Development, 76 (1), 47 - 54.

Weiner, J. P., Trish, E., Abrams, C. and Lemke, K. (2012). Adjusting For Risk Selection in State Health Insurance Exchanges will be Critically Important and Feasible, but Not Easy. Health Affairs, 31 (2), 306-315.

Winkelman, R. and DamleR, R. (2007). Risk adjustment in state medicaid programs. Health Watch, (57), 14-34. 


\section{Figure 1: Distribution of hospital charge differences between Blacks and Hispanics}

(a) Newborns

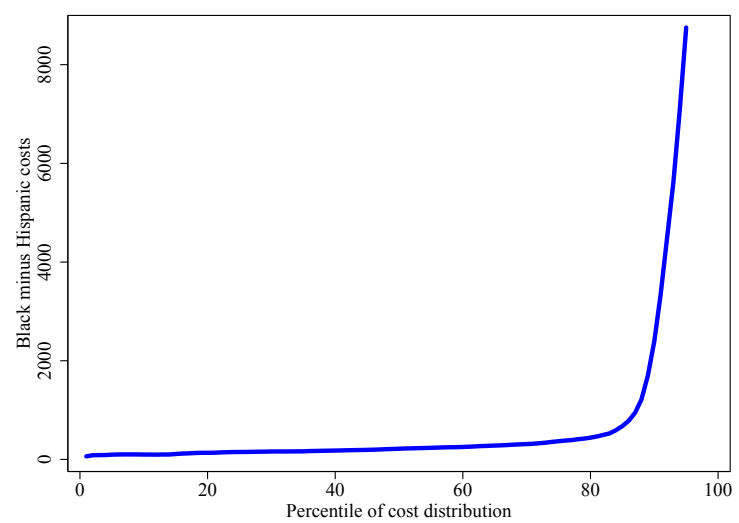

(b) Deliveries

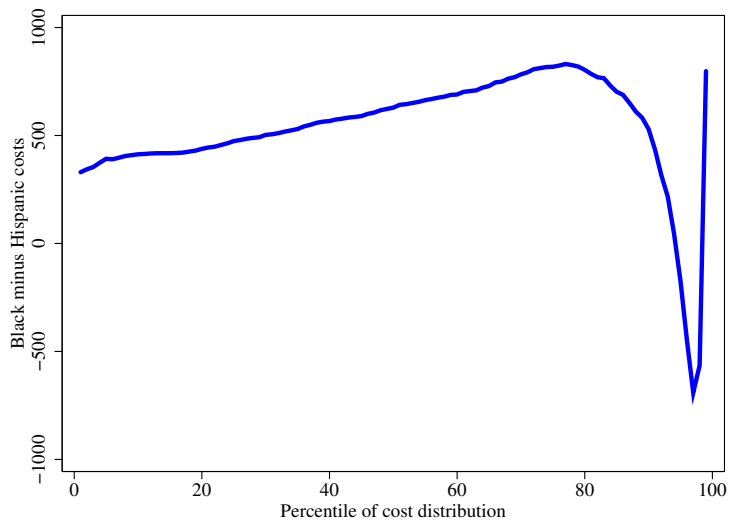

Notes: Figures are based on data from public-use Texas Hospital discharge data (see http://www.dshs.state.tx.us/THCIC/Hospitals/Download.shtm to download these data). For each graph, the value of the Hispanic $n^{t h}$ percentile is subtracted from the value of the Black $n^{t h}$ percentile.

Because of the extreme skewness of the newborn charges, the graph is truncated at the $95^{\text {th }}$ percentile. The black-Hispanic difference for the $99^{\text {th }}$ percentile is $\$ 76,341$. 
Figure 2: Changes in mortality for black and Hispanic births (note different scales)

(a) Blacks

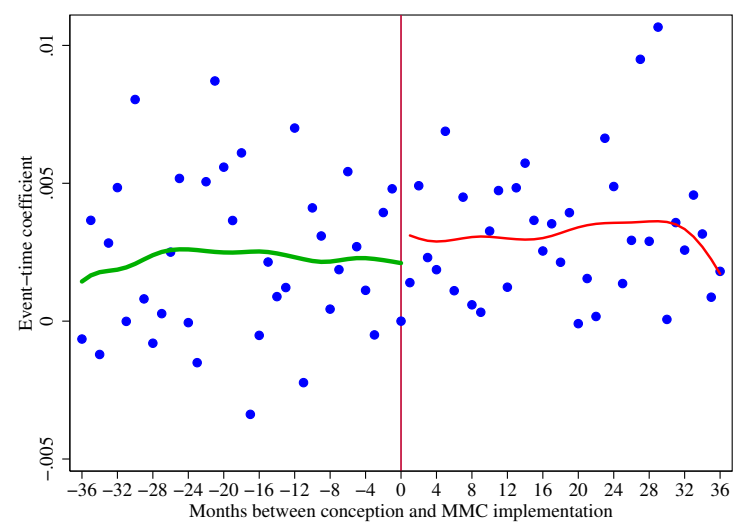

(b) Hispanics

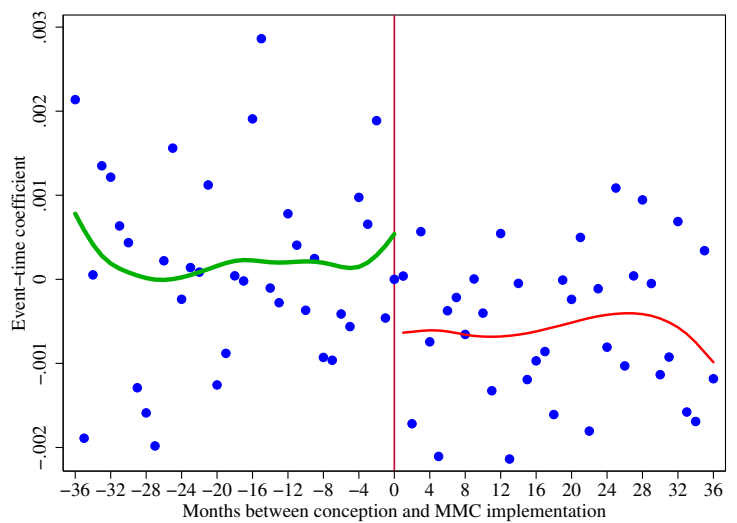

Notes: These figures show the results from estimating mortality rates for black (Figure a) and Hispanic (Figure b) births in the 36 months before and after MMC implementation. Specifically, we estimate the following equation:

$$
Y_{y m c}=\sum_{n=-36}^{-1} \beta_{n} \mathbf{I}_{c t}^{n}+\sum_{n=1}^{36} \beta_{n} \mathbf{I}_{c t}^{n}+\eta \text { Window } w_{c t}+\mu_{c}+\gamma_{y}+\nu_{m}+\mu_{c} * t+\epsilon_{y m c}
$$

where $\mathbf{I}_{t c}^{n}$ is an indicator variable for conceptions $n$ months after a county $c$ switched to MMC, meaning negative values of $n$ indicate conceptions in months before MMC implementation. Window is an indicator for being conceived within a six-year window of MMC's introduction (the range of the figure). This addition allows us to normalize conceptions the same month as MMC implementation to zero for ease of interpretation. (Excluding Window only shifts the level, not the shape, of the figures, as the excluded group by default becomes all births outside the graphs' six-year window.) The figure plots the $\beta_{n}$ coefficients along with lowess lines (of bandwidth one). Otherwise, the notation follows exactly from our main estimating equation (1) in the text: $c$ indexes counties, and $y$ and $m$ month and year; $Y_{y m c}$ is an outcome measure for county $c$ in year-month $y$ - $m$ (in this case, black and Hispanic mortality, respectively); $\mu_{c}$ are county fixed effects, $\gamma_{y}$ are conception-year fixed effects, and $\lambda_{m}$ are conception-month fixed effects; $\mu_{c} * t$ is the county-specific linear time-trend. 
Figure 3: Black share of all births before and after MMC

(a) With country linear time trends

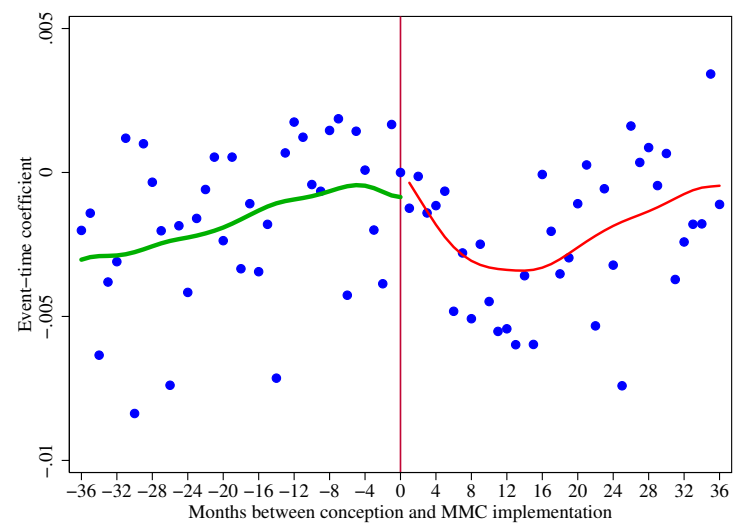

(b) Without county time trends

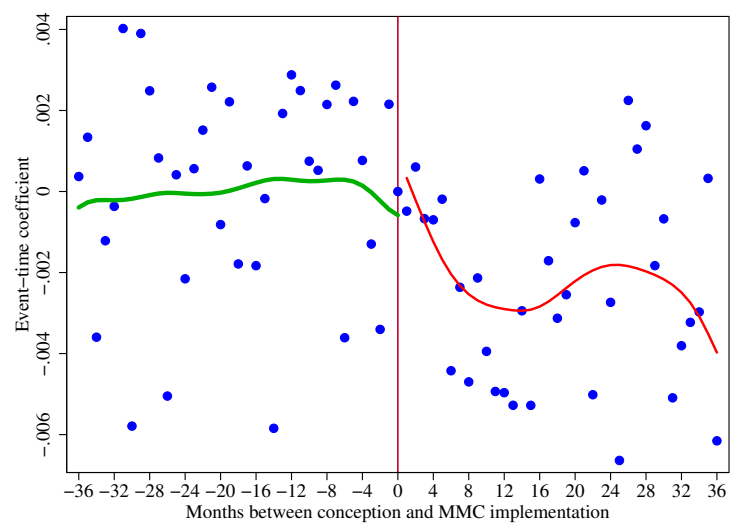

(c) With county quadratic time trends

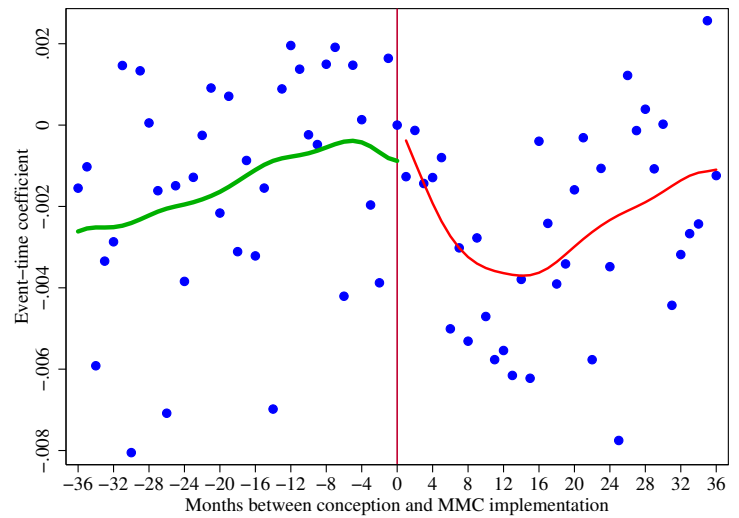

Notes: These figures show the results from estimating the effects on the share of black births in the 36 months before and after MMC implementation (the month of MMC implementation is normalized to zero). See the notes to Figure 2 for further details on the estimation procedure. Figure (a) includes country linear time trends (our standard specification), Figure (b) includes no county time trends, and Figure (c) includes county quadratic time trends. 
Figure 4: Changes in the male share of births (note different scales)

(a) Unnmarried black mothers

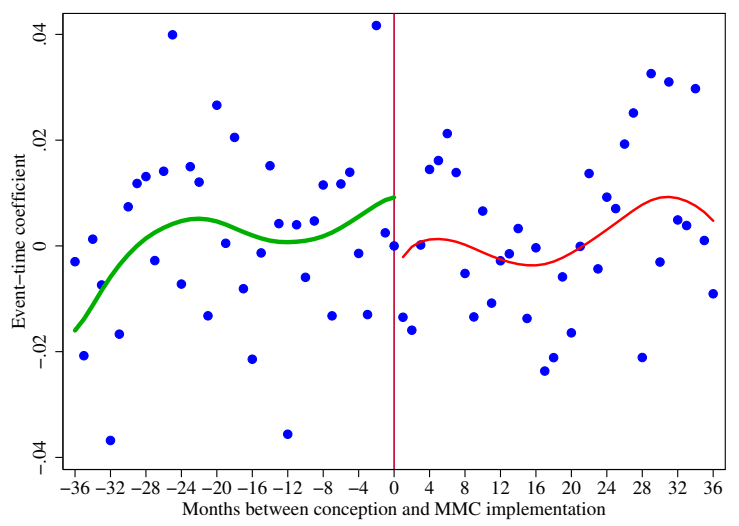

(b) Unmarried Hispanic mothers

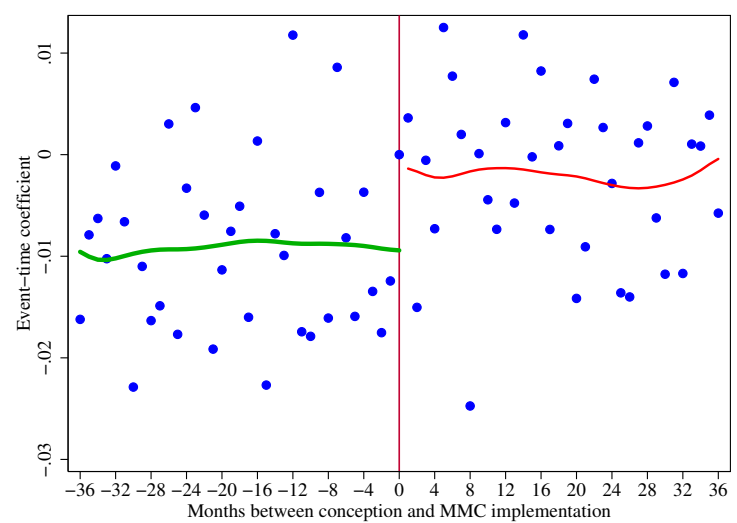

Notes: These figures show the results from estimating the effects on the male share of black (Figure a) and Hispanic (Figure b) births in the 36 months before and after MMC implementation (the month of MMC implementation is normalized to zero). See the notes to Figure 2 for further details on the estimation procedure. 
Table 1: Hospital charges for newborns and deliveries

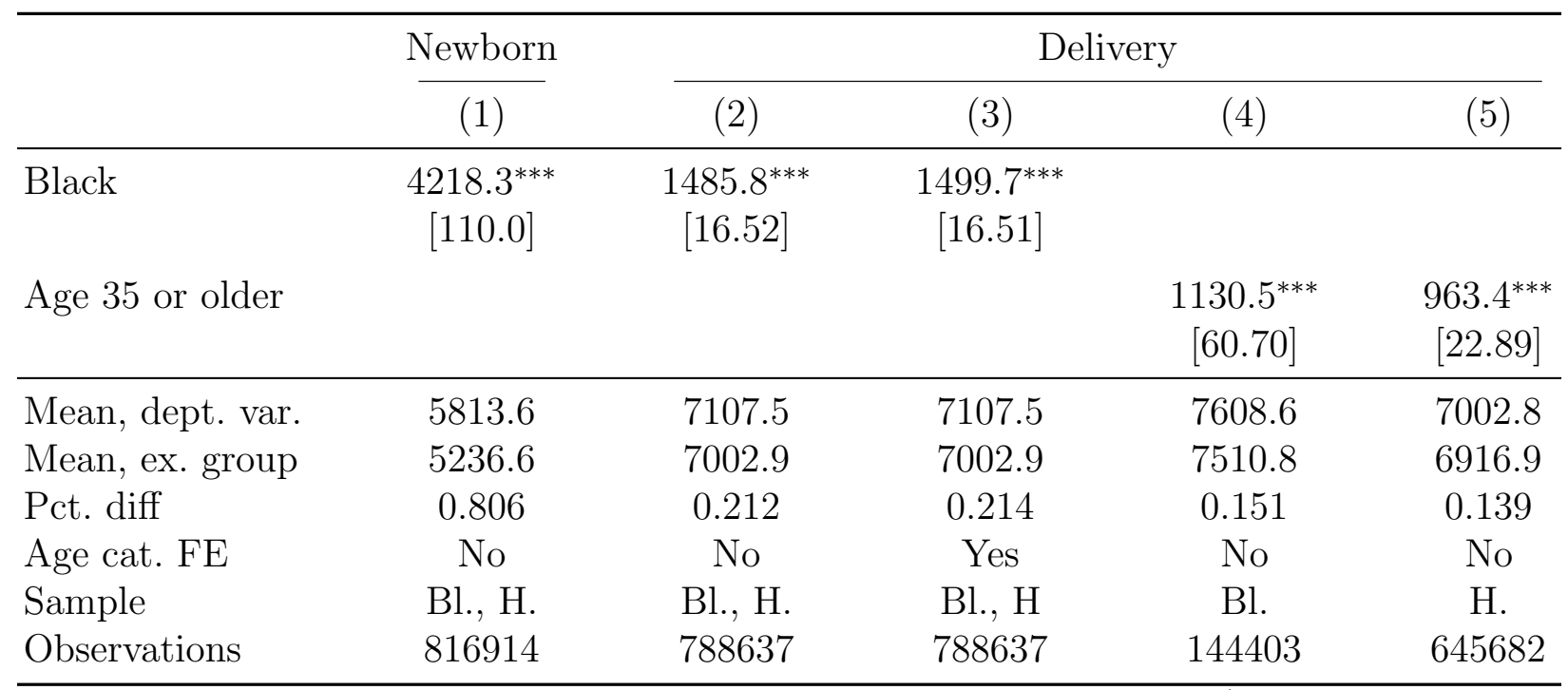

Notes: Regressions are based on data from public-use Texas Hospital discharge data (see http://www.dshs. state.tx.us/THCIC/Hospitals/Download.shtm to download these data). All regressions include county and year fixed effects and include all Hispanic and black births from the third quarter of 1999 through 2004 (county identifiers are missing in the first two quarters of 1999). Col. (3) includes maternal age fixed effects (age $<20$, age $\in[20,25)$, age $\in[25,30)$, age $\in[30,35)$, age $\geq 35)$. All means of the dependent variable are reported, as well as the percent difference between the group denoted by the reported regression coefficient (e.g., blacks, in col. 1) and the excluded group (e.g., Hispanics, in col. 1). That is, "Pct. Diff" just divides the coefficient by the excluded-group mean. Cols. (1) through (3) include all blacks and Hispanics, col. (4) includes only blacks and col. (5) includes only Hispanics. 
Table 2: Summary statistics

\begin{tabular}{|c|c|c|c|c|}
\hline & $\begin{array}{l}(1) \\
\text { All } \\
\end{array}$ & $\begin{array}{c}(2) \\
\text { Black } \\
\end{array}$ & $\begin{array}{c}(3) \\
\text { Hispanic }\end{array}$ & $\begin{array}{c}(4) \\
\text { Mar. white }\end{array}$ \\
\hline Mother's age & $\begin{array}{l}25.76 \\
(6.063)\end{array}$ & $\begin{array}{c}24.43 \\
(6.055)\end{array}$ & $\begin{array}{c}24.84 \\
(5.909)\end{array}$ & $\begin{array}{l}28.05 \\
(5.555)\end{array}$ \\
\hline $\begin{array}{l}\text { Low-birth weight } \\
\text { (Birthweight below } 2,500 \text { g.) }\end{array}$ & $\begin{array}{l}0.0724 \\
(0.259)\end{array}$ & $\begin{array}{c}0.125 \\
(0.331)\end{array}$ & $\begin{array}{l}0.0658 \\
(0.248)\end{array}$ & $\begin{array}{l}0.0599 \\
(0.237)\end{array}$ \\
\hline $\begin{array}{l}\text { Birthweight below } 2,500 \\
\text { g. or above } 4,000 \mathrm{~g} \text {. }\end{array}$ & $\begin{array}{c}0.159 \\
(0.365)\end{array}$ & $\begin{array}{c}0.174 \\
(0.379)\end{array}$ & $\begin{array}{c}0.145 \\
(0.352)\end{array}$ & $\begin{array}{c}0.174 \\
(0.379)\end{array}$ \\
\hline $\begin{array}{l}\text { Pre-term (Gestation less } \\
\text { than } 37 \text { weeks) }\end{array}$ & $\begin{array}{l}0.0923 \\
(0.289)\end{array}$ & $\begin{array}{c}0.133 \\
(0.340)\end{array}$ & $\begin{array}{l}0.0859 \\
(0.280)\end{array}$ & $\begin{array}{l}0.0859 \\
(0.280)\end{array}$ \\
\hline Any labor complications & $\begin{array}{c}0.168 \\
(0.374)\end{array}$ & $\begin{array}{c}0.187 \\
(0.390)\end{array}$ & $\begin{array}{c}0.159 \\
(0.366)\end{array}$ & $\begin{array}{c}0.168 \\
(0.374)\end{array}$ \\
\hline $\begin{array}{l}\text { Child died (death cert. } \\
\text { matched to birth cert.) }\end{array}$ & $\begin{array}{l}0.00725 \\
(0.0848)\end{array}$ & $\begin{array}{l}0.0121 \\
(0.109)\end{array}$ & $\begin{array}{l}0.00642 \\
(0.0799)\end{array}$ & $\begin{array}{l}0.00614 \\
(0.0781)\end{array}$ \\
\hline $\begin{array}{l}\text { Pre-natal care in first } \\
\text { trimester }\end{array}$ & $\begin{array}{c}0.784 \\
(0.412)\end{array}$ & $\begin{array}{c}0.746 \\
(0.436)\end{array}$ & $\begin{array}{c}0.714 \\
(0.452)\end{array}$ & $\begin{array}{c}0.902 \\
(0.298)\end{array}$ \\
\hline $\begin{array}{l}\text { Pre-natal care at public } \\
\text { clinic }\end{array}$ & $\begin{array}{c}0.126 \\
(0.332)\end{array}$ & $\begin{array}{c}0.133 \\
(0.340)\end{array}$ & $\begin{array}{c}0.191 \\
(0.393)\end{array}$ & $\begin{array}{l}0.0398 \\
(0.195)\end{array}$ \\
\hline $\begin{array}{l}\text { Pre-natal care at } \\
\text { hospital }\end{array}$ & $\begin{array}{c}0.172 \\
(0.378)\end{array}$ & $\begin{array}{c}0.251 \\
(0.434)\end{array}$ & $\begin{array}{c}0.212 \\
(0.409)\end{array}$ & $\begin{array}{l}0.0959 \\
(0.294)\end{array}$ \\
\hline $\begin{array}{l}\text { Pre-natal care at private } \\
\text { doctor's office }\end{array}$ & $\begin{array}{c}0.677 \\
(0.467)\end{array}$ & $\begin{array}{c}0.600 \\
(0.490)\end{array}$ & $\begin{array}{c}0.558 \\
(0.497)\end{array}$ & $\begin{array}{c}0.851 \\
(0.356)\end{array}$ \\
\hline $\begin{array}{l}\text { Use of fetal heart } \\
\text { monitor }\end{array}$ & $\begin{array}{c}0.853 \\
(0.354)\end{array}$ & $\begin{array}{c}0.823 \\
(0.382)\end{array}$ & $\begin{array}{c}0.860 \\
(0.347)\end{array}$ & $\begin{array}{c}0.847 \\
(0.360)\end{array}$ \\
\hline Use of fetal ventilator & $\begin{array}{l}0.0389 \\
(0.193)\end{array}$ & $\begin{array}{l}0.0507 \\
(0.219)\end{array}$ & $\begin{array}{l}0.0294 \\
(0.169)\end{array}$ & $\begin{array}{l}0.0475 \\
(0.213)\end{array}$ \\
\hline $\begin{array}{l}\text { Had ultrasound during } \\
\text { pregnancy }\end{array}$ & $\begin{array}{c}0.494 \\
(0.500)\end{array}$ & $\begin{array}{c}0.469 \\
(0.499)\end{array}$ & $\begin{array}{c}0.430 \\
(0.495)\end{array}$ & $\begin{array}{c}0.583 \\
(0.493)\end{array}$ \\
\hline $\begin{array}{l}\text { Had amnioscentisis during } \\
\text { pregnancy }\end{array}$ & $\begin{array}{l}0.0130 \\
(0.113)\end{array}$ & $\begin{array}{l}0.0115 \\
(0.106)\end{array}$ & $\begin{array}{l}0.00726 \\
(0.0849)\end{array}$ & $\begin{array}{l}0.0217 \\
(0.146)\end{array}$ \\
\hline Observations & $2,814,681$ & 320,534 & $1,263,661$ & 922,142 \\
\hline
\end{tabular}

Notes: This table reports means for key variables in the Texas birth records data. The sample of analysis includes births that were conceived by mothers residing in Texas between January 1993 and December 2001. 
Table 3: Effect of MMC on mortality rates $(\times 100)$ for black and Hispanic births

\begin{tabular}{lcccccc}
\hline & $(1)$ & $(2)$ & $(3)$ & $(4)$ & $(5)$ & $(6)$ \\
& Bl. & Hsp. & Bl. & Hsp. & Bl. & Hsp. \\
\hline Conceived after MMC & $0.136^{*}$ & $-0.1000^{* *}$ & $0.133^{*}$ & $-0.0947^{* *}$ & $0.242^{* *}$ & -0.114 \\
& {$[0.0695]$} & {$[0.0457]$} & {$[0.0709]$} & {$[0.0421]$} & {$[0.119]$} & {$[0.0731]$} \\
County unemp. rate & & & 0.0138 & -0.00783 & & \\
& & & {$[0.0474]$} & {$[0.00765]$} & & \\
Inc. per cap div. by & & & 0.0816 & $-0.0351^{* *}$ & & \\
1000 & & & {$[0.0566]$} & {$[0.0139]$} & & \\
Population div. by & & & -0.0959 & $-0.156^{* *}$ & & \\
100,000 & & & {$[0.226]$} & {$[0.0705]$} & & \\
\hline Dept. var mean & 1.208 & 0.642 & 1.208 & 0.642 & 1.283 & 0.750 \\
Sample & All & All & All & All & Unmar. & Unmar. \\
Diff/p-val & 0.236 & 0.000706 & 0.228 & 0.000997 & 0.355 & 0.00305 \\
Reg. obs (cells) & 12955 & 22818 & 12955 & 22818 & 11806 & 18479 \\
Indiv. obs. & 318144 & 1263661 & 318144 & 1263661 & 196875 & 419026 \\
\hline
\end{tabular}

Notes: These regressions are based on Texas birth records data. The sample of analysis includes births that were conceived by mothers residing in Texas between January 1993 and December 2001. Units of observation are county/conception-year/conception-month cells and all regressions are weighted by cell size. All regressions include year, month and county fixed effects, and county-specific linear time trends. Standard errors are clustered by county. The "Diff/p-val" row shows in the odd-numbered columns the differences in the black-Hispanic $M M C$ coefficients and the even-numbered columns present the $p$-value associated with the test of equality across the two coefficients. 
Table 4: Effect of MMC on other birth outcomes $(\times 100)$ for black and Hispanic births

\begin{tabular}{|c|c|c|c|c|c|c|c|c|}
\hline & \multicolumn{2}{|c|}{ LBW } & \multicolumn{2}{|c|}{ Abn. BW } & \multicolumn{2}{|c|}{ Pre-term } & \multicolumn{2}{|c|}{ Complic. } \\
\hline & (1) & $(2)$ & (3) & $(4)$ & (5) & $(6)$ & (7) & (8) \\
\hline & Bl. & Hsp. & Bl. & Hsp. & Bl. & Hsp. & Bl. & Hsp. \\
\hline Conc & $0.696^{*}$ & -0.0854 & $0.901^{* *}$ & -0.227 & $0.937^{* *}$ & -0.115 & $3.114^{* * *}$ & $3.881^{*}$ \\
\hline MMC & {$[0.399]$} & {$[0.0876]$} & {$[0.350]$} & {$[0.343]$} & {$[0.362]$} & {$[0.277]$} & {$[1.080]$} & {$[2.196]$} \\
\hline Dept. & 12.53 & 6.581 & 17.38 & 14.49 & 13.37 & 8.595 & 18.72 & 15.90 \\
\hline Diff/p-ז & 0.782 & 0.00242 & 1.128 & 0.0303 & 1.052 & 0.0327 & -0.768 & 0.731 \\
\hline Reg. obs (cells) & 12950 & 22815 & 12950 & 22815 & 12955 & 22818 & 12655 & 22305 \\
\hline Indiv. obs. & 318139 & 1263658 & 318139 & 1263658 & 318144 & 1263661 & 312095 & 1244639 \\
\hline
\end{tabular}

Notes: See notes under Table 3 for more details about the data, sample, and specifications. "LBW" denotes birth weight < 2,500g; "Abn. BW" (abnormal birthweight) denotes birthweight $<2,500 \mathrm{~g}$ or $>4,000 \mathrm{~g}$; "Pre-term" denotes gestation $<37$ weeks; "Complic" denotes any birth complications.

Table 5: Changes in risk-factors $(\times 100)$ after MMC for black and Hispanic births

\begin{tabular}{|c|c|c|c|c|c|c|}
\hline & \multicolumn{2}{|c|}{ Over age 35} & \multicolumn{2}{|c|}{ Diab/Hypert. } & \multicolumn{2}{|c|}{ Smoker } \\
\hline & (1) & $(2)$ & (3) & $(4)$ & (5) & $(6)$ \\
\hline & Bl. & Hsp. & Bl. & Hsp. & Bl. & Hsp. \\
\hline Conceived after & $-0.511^{*}$ & $-0.221^{* * *}$ & -0.115 & $-0.252^{*}$ & -0.359 & 0.155 \\
\hline $\mathrm{MMC}$ & {$[0.286]$} & {$[0.0793]$} & {$[0.163]$} & {$[0.140]$} & {$[0.245]$} & {$[0.167]$} \\
\hline Dept. var mean & 6.271 & 6.048 & 3.506 & 3.228 & 6.008 & 2.246 \\
\hline Diff/p-val & -0.291 & 0.0499 & 0.137 & 0.384 & -0.515 & 0.00723 \\
\hline Reg. obs (cells) & 12954 & 22817 & 12955 & 22818 & 12929 & 22804 \\
\hline Indiv. obs. & 318143 & 1263660 & 318144 & 1263661 & 318117 & 1263646 \\
\hline
\end{tabular}

Notes: See notes under Table 3 for more details about the data, sample, and specifications. 
Table 6: Effect of MMC on pre-natal care measures $(\times 100)$ for black and Hispanic births

\begin{tabular}{|c|c|c|c|c|c|c|c|c|}
\hline & \multicolumn{2}{|c|}{ Fetal mon. } & \multicolumn{2}{|c|}{ Ventilator } & \multicolumn{2}{|c|}{ Ultrasound } & \multicolumn{2}{|c|}{ Amnio. } \\
\hline & (1) & $(2)$ & (3) & $(4)$ & (5) & (6) & (7) & (8) \\
\hline & $\mathrm{Bl}$. & Hsp. & Bl. & Hsp. & $\mathrm{Bl}$. & Hsp. & Bl. & Hsp. \\
\hline Born under MMC & $\begin{array}{l}-1.937 \\
{[1.176]}\end{array}$ & $\begin{array}{c}0.717 \\
{[1.363]}\end{array}$ & $\begin{array}{c}-1.341^{* * *} \\
{[0.501]}\end{array}$ & $\begin{array}{l}-0.981 \\
{[0.670]}\end{array}$ & $\begin{array}{c}-5.452^{* * *} \\
{[1.408]}\end{array}$ & $\begin{array}{l}-1.151 \\
{[1.376]}\end{array}$ & $\begin{array}{l}-0.140 \\
{[0.112]}\end{array}$ & $\begin{array}{c}0.156^{*} \\
{[0.0797]}\end{array}$ \\
\hline Dept. var mean & 82.26 & 86.02 & 5.070 & 2.944 & 46.84 & 42.97 & 1.151 & 0.726 \\
\hline Diff/p-val & -2.653 & 0.0555 & -0.359 & 0.566 & -4.301 & 0.0113 & -0.296 & 0.000201 \\
\hline Reg. obs (cells) & 12955 & 22818 & 12955 & 22818 & 12955 & 22818 & 12955 & 22818 \\
\hline Indiv. obs. & 318144 & 1263661 & 318144 & 1263661 & 318144 & 1263661 & 318144 & 1263661 \\
\hline
\end{tabular}

Notes: See notes under Table 3 for more details about the data, sample, and specifications. Note that the key explanatory variable of interest is an indicator for being born after (rather than conceived after) MMC.

Table 7: Effect of MMC on site of pre-natal care $(\times 100)$ on black and Hispanic births

\begin{tabular}{|c|c|c|c|c|c|c|}
\hline & \multicolumn{2}{|c|}{ Pub. Clinic } & \multicolumn{2}{|c|}{ Hosp. } & \multicolumn{2}{|c|}{ Private } \\
\hline & (1) & $(2)$ & (3) & $(4)$ & (5) & $(6)$ \\
\hline & Bl. & Hsp. & Bl. & Hsp. & Bl. & Hsp. \\
\hline Born under MMC & $\begin{array}{l}3.574^{* *} \\
{[1.605]}\end{array}$ & $\begin{array}{c}2.658 \\
{[3.135]}\end{array}$ & $\begin{array}{c}-1.673^{* * *} \\
{[0.505]}\end{array}$ & $\begin{array}{l}-4.114^{*} \\
{[2.393]}\end{array}$ & $\begin{array}{l}-0.552 \\
{[0.687]}\end{array}$ & $\begin{array}{c}0.424 \\
{[1.091]}\end{array}$ \\
\hline Dept. var mean & 13.39 & 19.17 & 25.17 & 21.13 & 59.85 & 55.66 \\
\hline Diff/p-val & 0.915 & 0.768 & 2.441 & 0.386 & -0.976 & 0.412 \\
\hline Reg. obs (cells) & 12655 & 22305 & 12655 & 22305 & 12655 & 22305 \\
\hline Indiv. obs. & 312095 & 1244639 & 312095 & 1244639 & 312095 & 1244639 \\
\hline
\end{tabular}

Notes: See notes under Table 3 for more details about the data, sample, and specifications. Note that the key explanatory variable of interest is an indicator for being born after (rather than conceived after) MMC. 
Table 8: Effect of MMC on black birth rates

\begin{tabular}{|c|c|c|c|c|c|c|}
\hline & \multicolumn{3}{|c|}{ Share black } & \multicolumn{3}{|c|}{$\log$} \\
\hline & $\begin{array}{c}(1) \\
\text { Black }\end{array}$ & $\begin{array}{l}(2) \\
\text { Bl. unm. }\end{array}$ & $\begin{array}{l}(3) \\
\text { Bl. unm. }\end{array}$ & $\begin{array}{c}(4) \\
\text { Black }\end{array}$ & $\begin{array}{c}\text { (5) } \\
\text { Bl. unm. }\end{array}$ & $\begin{array}{c}(6) \\
\text { Non-bl. }\end{array}$ \\
\hline $\begin{array}{l}\text { Conceived after } \\
\text { MMC }\end{array}$ & $\begin{array}{l}-0.00196^{* *} \\
{[0.000786]}\end{array}$ & $\begin{array}{r}-0.00276^{* * *} \\
{[0.000809]}\end{array}$ & $\begin{array}{r}-0.00257^{* * *} \\
{[0.000612]}\end{array}$ & $\begin{array}{c}-0.0352^{* * *} \\
{[0.0114]}\end{array}$ & $\begin{array}{c}-0.0481^{* * *} \\
{[0.00794]}\end{array}$ & $\begin{array}{l}-0.0134 \\
{[0.0113]}\end{array}$ \\
\hline County unemp. rate & & & $\begin{array}{l}-0.0274^{*} \\
{[0.0143]}\end{array}$ & & & \\
\hline $\begin{array}{l}\text { County per cap. } \\
\text { income (div. by } 10,000 \text { ) }\end{array}$ & & & $\begin{array}{c}-0.00921^{* *} \\
{[0.00392]}\end{array}$ & & & \\
\hline $\begin{array}{l}\text { County population } \\
\text { (div. by } 100,000 \text { ) }\end{array}$ & & & $\begin{array}{c}-0.00917^{*} \\
{[0.00475]}\end{array}$ & & & \\
\hline Mean, dept. var. & 0.113 & 0.0699 & 0.0699 & 5.632 & 5.136 & 7.050 \\
\hline Reg. obs. (cells) & 26021 & 26021 & 26021 & 3672 & 3672 & 3672 \\
\hline Indiv. obs. & 2814681 & 2814681 & 2814681 & 278780 & 170500 & 1618301 \\
\hline
\end{tabular}

Notes: These regressions are based on Texas birth records data. The sample of analysis includes births that were conceived by mothers residing in Texas between January 1993 and December 2001. Units of observation are county/conception-year/conception-month cells. In all columns except when share of births is the outcome, all county/year/month cells in Texas between 1993 and 2001 are included and each cell is weighted by cell size. When logs are used in cols. (4) through (6), counties are restricted to those with at least one black unmarried birth in each month (to avoid taking the log of zero and to have a consistent sample of counties), a sample which accounts for 67 percent of all births and 87 percent of black unmarried births. Col. (4) is weighted by the number of black births in a county/year/month, col. (5) is weighted by the number of black unmarried births in a county/year/month, and column (6) is weighted by the number of non-black births in a county/year/month. All regressions include year, month and county fixed effects, and county-specific linear time trends. Standard errors are clustered by county. 
Table 9: Effect of MMC on male share of births

\begin{tabular}{lcccc}
\hline & $(1)$ & $(2)$ & $(3)$ & $(4)$ \\
& Black & Bl. unmar. & Hisp. & H. unmar. \\
\hline Conceived after & -0.349 & -0.459 & 0.268 & $0.724^{* *}$ \\
MMC & {$[0.512]$} & {$[0.549]$} & {$[0.347]$} & {$[0.312]$} \\
\hline Mean, dept. var & 50.92 & 50.91 & 51.03 & 51.06 \\
Reg. obs. (cells) & 12955 & 11806 & 22818 & 18479 \\
Indiv. obs. & 318144 & 196875 & 1263661 & 419026 \\
\hline
\end{tabular}

Notes: See notes under Table 3 for more details about the data, sample, and specifications.

Table 10: Effect of MMC on abortion rates $(\times 100)$

\begin{tabular}{lccccccc}
\hline & \multicolumn{6}{c}{ Dept. var: Share of conceptions ending in abortion } \\
\cline { 2 - 8 } & $(1)$ & $(2)$ & $(3)$ & $(4)$ & $(5)$ & $(6)$ & $(7)$ \\
& Black & Bl. unm. & Bl. mar. & Bl. unm. & Bl. unm. & Hisp & H. unm. \\
\hline Conceived after or 3 & $1.886^{* *}$ & $3.083^{* * *}$ & -0.682 & $2.809^{* * *}$ & $1.404^{* *}$ & -0.242 & 0.258 \\
mos. before MMC & {$[0.795]$} & {$[0.752]$} & {$[0.636]$} & {$[0.721]$} & {$[0.607]$} & {$[0.600]$} & {$[1.231]$} \\
\hline Mean, dept. var. & 27.87 & 34.67 & 13.29 & 34.68 & 34.67 & 12.79 & 24.77 \\
County trends & Yes & Yes & Yes & Yes & No & Yes & Yes \\
Early cut-off & No & No & No & Yes & No & No & No \\
Reg obs. (cells) & 6134 & 5649 & 4076 & 5406 & 5649 & 10397 & 8913 \\
Indiv. obs. & 198998 & 135732 & 63266 & 129950 & 135732 & 704902 & 278956 \\
\hline
\end{tabular}

Notes: These regressions are based on Texas abortion and birth records data. The sample of analysis includes births that were conceived by mothers residing in Texas between January 1998 and December 2001, since abortions only began to be reported then. Units of observation are county/conception-year/conception-month cells and all regressions are weighted by cell size. All regressions include year, month and county fixed effects and all but col. (5) include linear county time trends. Standard errors are clustered by county. 


\section{Appendix Figure 1: Black share of population ages 2-17 (IPUMS data)}

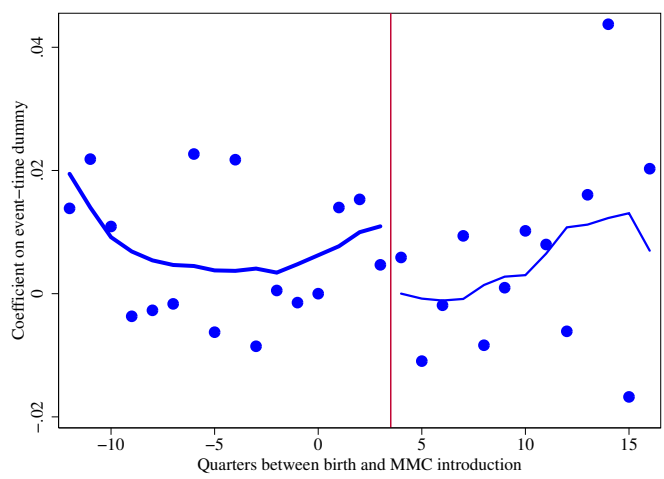

Notes: These data are taken from the 2005-2011 IPUMS, restricted to individuals born in Texas. Linear birth-date (measured at the quarter level) county trends are included (the analogue to county linear trends in conception month in the birth-certificate analysis), as well as county and year- and quarter-of-birth fixed effects. Conception corresponds to births three-quarters after MMC implementation, so we divide the lowess lines at that point. The youngest cohort to be born during an MMC transition year would be five to six years old in 2005 (from those counties switching in 1999) and the oldest would be fourteen to fifteen in 2011 (from those counties switching in December 1995). As such, we include ages slightly below and above these cut-offs respectively, just as in the birth-certificate analysis we include about three years before and after the first and last set of counties switch, respectively. 
Appendix Table 1: Roll Out Schedule for Texas MMC

\begin{tabular}{|c|c|}
\hline Date & Counties \\
\hline Aug 1993 & Travis \\
\hline Dec 1993 & Chambers Jefferson Galveston \\
\hline Dec 1995 & Liberty, Hardin, Orange \\
\hline \multirow[t]{5}{*}{ Sep 1996} & Burnet Williamson Lee Bastrop Fayette Caldwell \\
\hline & Hays Lubbock Terry Lynn Garza Crosby Hockley Llano Hale \\
\hline & Floyd Swisher Randall Deaf Smith Potter Hutshinson Carson \\
\hline & Bexar Atascosa Wilson Guadalupe Comal Kendall Bandera \\
\hline & Medina Tarrant Hood Parker Wise Denton Johnson \\
\hline Dec 1997 & Houston \\
\hline Mar 1998 & $\begin{array}{l}\text { Harris Galveston Brazoria Matagorda Wharton Fort Bend } \\
\text { Austin Waller Montgomery }\end{array}$ \\
\hline Jan 1999 & $\begin{array}{l}\text { Dallas Ellis Navarro Kaufman Rockwall Hunt Collin El Paso } \\
\text { Hudspeth }\end{array}$ \\
\hline \multirow[t]{2}{*}{ Jan 2006} & Nueces Kenedy Brooks Kleberg Jim Wells San Patricio \\
\hline & Live Oak Aransas Refugio Bee Goliad Victoria Karnes Calhoun \\
\hline
\end{tabular}

Notes: This information was obtained from Chapter 6 of the report available here: www.hhsc.state.tx.us/ medicaid/reports/PB8/PinkBookTOC.html

Appendix Table 2: Estimated Medicaid share of births in 2005

\begin{tabular}{|c|c|c|c|c|}
\hline & $\begin{array}{l}(1) \\
\text { All }\end{array}$ & $\begin{array}{c}(2) \\
\text { Black }\end{array}$ & $\begin{array}{c}(3) \\
\text { Hispanic }\end{array}$ & $\begin{array}{c}(4) \\
\text { White }\end{array}$ \\
\hline Medicaid share of births & 0.539 & 0.791 & 0.584 & 0.437 \\
\hline $\begin{array}{l}\text { Medicaid share of births, } \\
\text { married mothers }\end{array}$ & 0.360 & 0.429 & 0.465 & 0.269 \\
\hline Observations & 273471 & 29262 & 133756 & 100526 \\
\hline \multicolumn{5}{|c|}{$\begin{array}{l}\text { Notes: Texas does not record Medicaid status on birth certificates until } 2005 \text {. As we discuss in Section } 4 \text {, } \\
\text { these numbers appear substantially under-reported, almost certainly due to women or providers who are on } \\
\text { privatized Medicaid mistakenly reporting that the birth is covered by a private insurer instead of Medicaid. } \\
\text { In } 2005 \text {, the Texas Health and Human Services Commission reported that } 54 \text { percent of births were covered } \\
\text { by Medicaid, whereas the birth certificate data indicate that only } 41 \text { percent were. We thus "gross up" the } \\
\text { Medicaid share by } 1.3 \text { in this table. See Section } 4 \text { for additional evidence that the shift from FFS to MMC } \\
\text { results in substantial under-reporting of Medicaid births. }\end{array}$} \\
\hline
\end{tabular}


Appendix Table 3: Effect of MMC on birth outcomes $(\times 100)$ for married whites

\begin{tabular}{lcccccccc}
\hline & $(1)$ & $(2)$ & $(3)$ & $(4)$ & $(5)$ & $(6)$ & $(7)$ & $(8)$ \\
& Mort. & LBW & ABW & Pret. & Comp. & Male & Abort & Old \\
\hline Conceived after & 0.0533 & 0.0329 & -0.0397 & 0.257 & 0.684 & -0.113 & & 0.0277 \\
MMC & {$[0.0459]$} & {$[0.151]$} & {$[0.182]$} & {$[0.214]$} & {$[0.712]$} & {$[0.199]$} & & {$[0.209]$} \\
& & & & & & & & \\
Conc. after or & & & & & & & -0.0524 & \\
three mos. prior & & & & & & & {$[0.534]$} & \\
\hline Mean, dept. var & 0.614 & 5.991 & 17.44 & 8.589 & 16.88 & 51.27 & 4.575 & 11.45 \\
Reg. obs. (cells) & 23898 & 23894 & 23894 & 23898 & 23347 & 23898 & 10372 & 23898 \\
Underlying & 922142 & 922138 & 922138 & 922142 & 902860 & 922142 & 417211 & 922142 \\
\hline
\end{tabular}

Notes: These regressions are based on Texas birth records data. The sample of analysis includes births that were conceived by mothers residing in Texas between January 1993 and December 2001. Units of observation are county/conception-year/conception-month cells and all regressions are weighted by cell size. All regressions include year, month and county fixed effects, and county-specific linear time trends. Standard errors are clustered by county. "Mort" denotes a death certificate was matched to the birth cerficite; "LBW" denotes birth weight < 2,500g; "ABW" (abnormal birthweight) denotes birthweight $<2,500 \mathrm{~g}$ or $>4,000$ g; "Pret" denotes pre-term birth; "Comp" denotes any birth complications; "Male" denotes infant's gender; "Abort" denotes that the conception was aborted and thus includes the universe of conceptions beginning in 1998 (when abortion month begins to be recorded); "Old" denotes mother's age $\geq 35$.

Appendix Table 4: Effect of MMC on black birth outcomes after controlling for covariates

\begin{tabular}{lccccc}
\hline & $(1)$ & $(2)$ & $(3)$ & $(4)$ & $(5)$ \\
& Mort. & LBW & ABW & Pret. & Any comp. \\
\hline Conceived after & $0.145^{* *}$ & $0.789^{*}$ & $0.981^{* * *}$ & $0.981^{* * *}$ & $3.189^{* * *}$ \\
MMC & {$[0.0716]$} & {$[0.408]$} & {$[0.350]$} & {$[0.366]$} & {$[1.063]$} \\
\hline Mean, dept. var. & 1.208 & 12.53 & 17.38 & 13.37 & 18.67 \\
Observations & 318144 & 317793 & 317793 & 318144 & 308497 \\
\hline
\end{tabular}

Notes: These regressions are based on individual-level Texas birth records data. The sample of analysis includes births that were conceived by mothers residing in Texas between January 1993 and December 2001. All regressions include the typical controls in the cell-aggregated regressions (county, year, and month fixed effects and county time trends) as well as the following individual-level controls: indicators for married and first-parity child, age (in four-year bins) fixed effects, and educational attainment fixed effects (no high school education, high school education, some college and college graduate). Standard errors are clustered by county. 
Appendix Table 5: Effect of MMC on Hispanic birth outcomes after controlling for covariates

\begin{tabular}{lccccc}
\hline & $(1)$ & $(2)$ & $(3)$ & $(4)$ & $(5)$ \\
& Mort. & LBW & ABW & Pret. & Any comp. \\
\hline Conceived after & $-0.0941^{* *}$ & -0.00838 & -0.187 & -0.0563 & $4.007^{*}$ \\
MMC & {$[0.0471]$} & {$[0.0991]$} & {$[0.342]$} & {$[0.288]$} & {$[2.131]$} \\
\hline Mean, dept. var. & 0.642 & 6.581 & 14.49 & 8.595 & 15.89 \\
Observations & 1263661 & 1263114 & 1263114 & 1263661 & 1231496 \\
\hline
\end{tabular}

Notes: These regressions are based on individual-level Texas birth records data. The sample of analysis includes births that were conceived by mothers residing in Texas between January 1993 and December 2001. All regressions include the typical controls in the cell-aggregated regressions (county, year, and month fixed effects and county time trends) as well as the following individual-level controls: indicators for married and first-parity child, age (in four-year bins) fixed effects, and educational attainment fixed effects (no high school education, high school education, some college and college graduate). Standard errors are clustered by county.

Appendix Table 6: Effect of MMC on birth inputs $(\times 100)$ for married whites

\begin{tabular}{lccccc}
\hline & $(1)$ & $(2)$ & $(3)$ & $(4)$ & $(5)$ \\
& Fet. mon. & Vent. & Ultrasound & Amnio. & Pub. clinic \\
\hline Born under MMC & 0.591 & $-1.523^{* * *}$ & -3.442 & -0.0568 & 0.00240 \\
& {$[1.074]$} & {$[0.547]$} & {$[3.090]$} & {$[0.178]$} & {$[0.00179]$} \\
\hline Mean, dept. var & 84.70 & 4.753 & 58.31 & 2.171 & 0.0401 \\
Reg. obs. (cells) & 23898 & 23898 & 23898 & 23898 & 23347 \\
Indiv. obs. & 922142 & 922142 & 922142 & 922142 & 902860 \\
\hline
\end{tabular}

Notes: These regressions are based on Texas birth records data. The sample of analysis includes births that were conceived by mothers residing in Texas between January 1993 and December 2001. Units of observation are county/conception-year/conception-month cells and all regressions are weighted by cell size. All regressions include year, month and county fixed effects, and county-specific linear time trends. Standard errors are clustered by county. 
Appendix Table 7: Changes in black share of school enrollment after MMC

(1)

$(2)$

(3)

Share black Log bl. enrollment Log bl. enroll (w 0s)

\begin{tabular}{lccc}
\hline After MMC & -0.000896 & 0.00362 & 0.00511 \\
& {$[0.000871]$} & {$[0.0117]$} & {$[0.0124]$} \\
\hline Mean, dept. var. & 0.140 & 8.667 & 8.644 \\
Number county-year cells & 2738 & 2588 & 2738 \\
\hline
\end{tabular}

Notes: These data come from the National Center of Education Statistics. Units of observation are countyyear cells. All regressions are weighted by total enrollment in each cell. The sample of analysis includes school enrollment data from all Texas counties except for the four pilot counties over 1992-1993 to 2001-2002. In the "Log bl. enroll (w 0s)" specifications, cells with 0 values are recoded to 1 . All regressions include county and year fixed effects and county-specific linear time trends. Standard errors are clustered by county. 